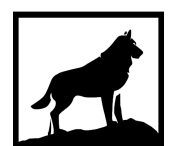

Michigan Technological

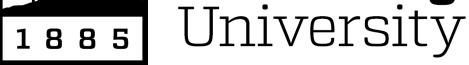

Michigan Technological University Digital Commons @ Michigan Tech

ONLINE MAPPING APPLICATION DEVELOPMENT FOR THE SCHOOL OF FOREST RESOURCES AND ENVIRONMENTAL SCIENCE GEOSPATIAL DATA

Aysen Sozen

Michigan Technological University, asozen@mtu.edu

Copyright 2017 Aysen Sozen

Recommended Citation

Sozen, Aysen, "ONLINE MAPPING APPLICATION DEVELOPMENT FOR THE SCHOOL OF FOREST RESOURCES AND ENVIRONMENTAL SCIENCE GEOSPATIAL DATA", Open Access Master's Thesis, Michigan Technological University, 2017.

https://doi.org/10.37099/mtu.dc.etdr/544

Follow this and additional works at: https://digitalcommons.mtu.edu/etdr

Part of the Geographic Information Sciences Commons 


\title{
ONLINE MAPPING APPLICATION DEVELOPMENT FOR THE SCHOOL OF FOREST RESOURCES AND ENVIRONMENTAL SCIENCE GEOSPATIAL DATA
}

\author{
By \\ Aysen Sozen

\begin{abstract}
A THESIS
Submitted in partial fulfillment of the requirements for the degree of
\end{abstract} \\ MASTER OF GEOGRAPHIC INFORMATION SCIENCE
}

MICHIGAN TECHNOLOGICAL UNIVERSITY

2017

C2017 AYSEN SOZEN 
This thesis has been approved in partial fulfillment of requirements for the Degree of MASTER OF GEOGRAPHIC INFORMATION SCIENCE.

School of Forest Resources and Environmental Science

Thesis Advisor:

Committee Member:

Committee Member:

School Dean:
Dr. Ann L. Maclean

Dr. Curtis Edson

Mike Hyslop

Dr. Terry Sharik 


\section{Table of Contents}

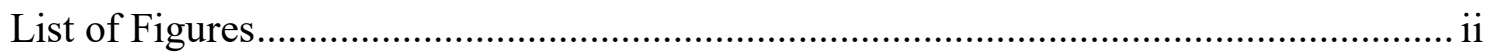

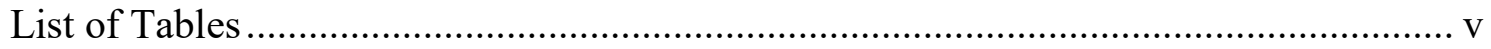

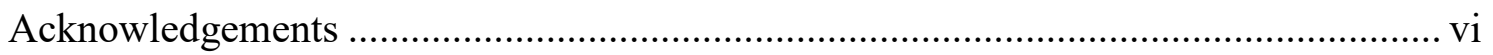

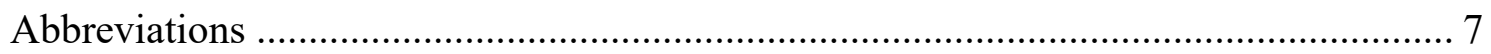

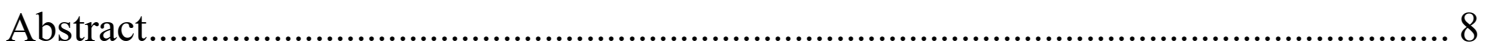

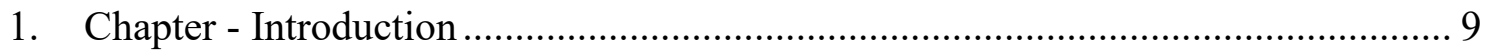

1.1. Importance of GIS .............................................................................. 9

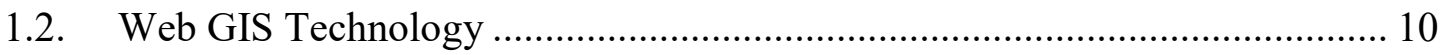

1.3. Database Design and Construction ............................................................... 11

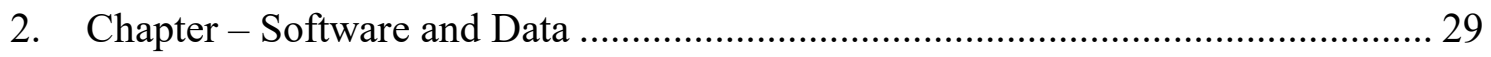

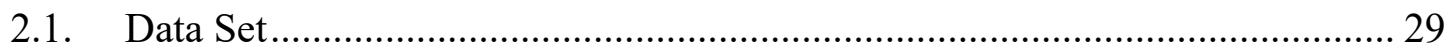

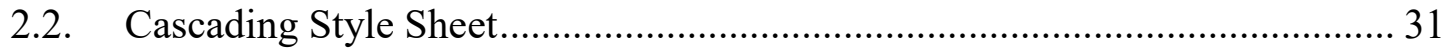

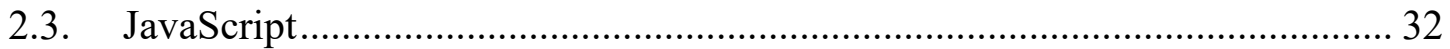

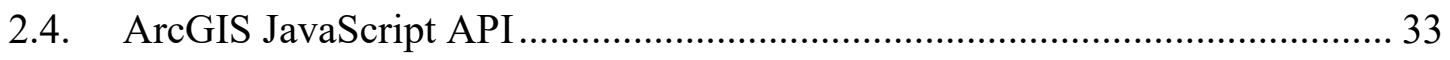

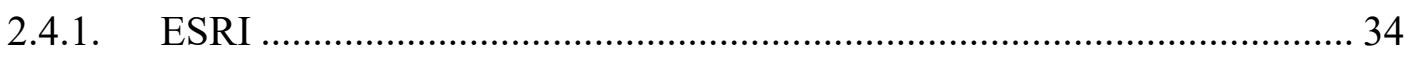

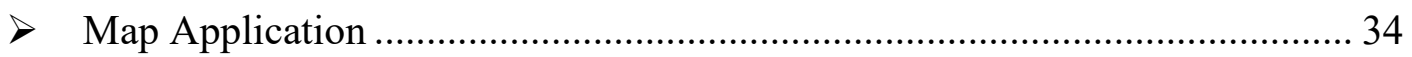

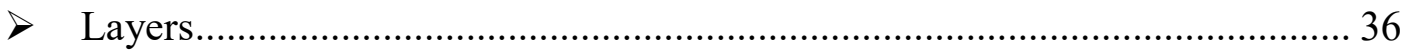

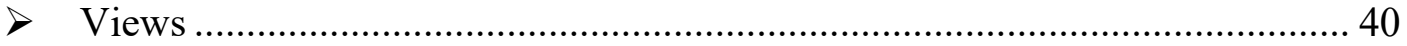

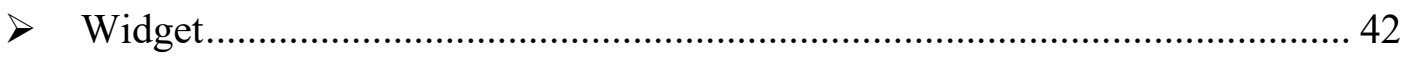

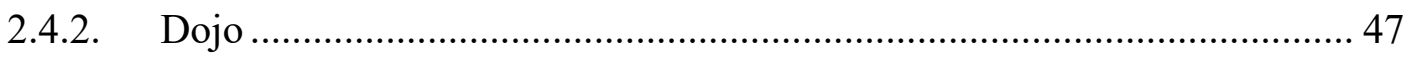

$>$ On

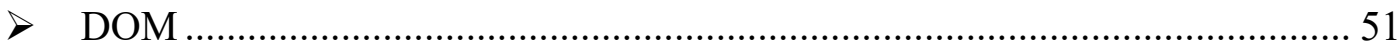

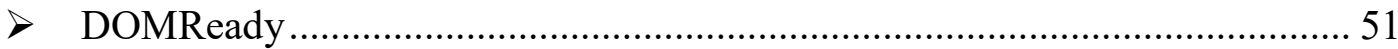

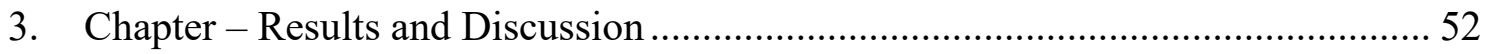

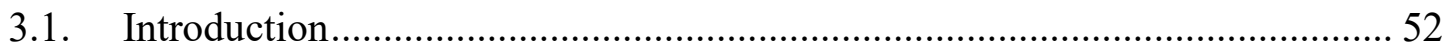

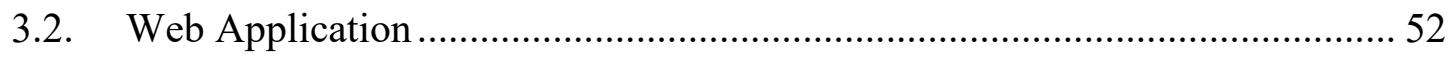

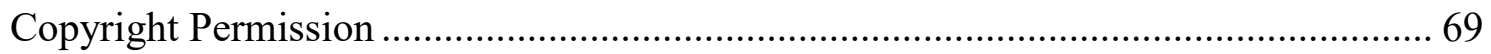

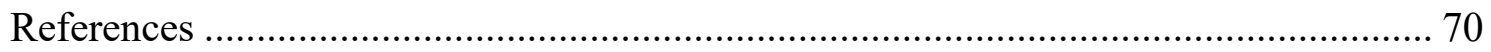




\section{List of Figures}

Figure 1.1. Architecture of A Single ArcGIS Server Machine (C) 2017 Esri (ESRI, ArcGIS Enterprise, Installation Guides, Single-machine deployment 2017)................ 12 Figure 1.2. Architecture of Multiple ArcGIS Servers in Multiple-Machine (C 2017 Esri (ESRI, ArcGIS Enterprise, Installation Guides, Multiple-machine deployment with ArcGIS Web Adaptor 2017).................................................................................. 13 Figure 1.3. SFRES Geospatial Data - ArcGIS for Server main access point (ArcGIS REST Services Directory Interface of The SFRES Geospatial Data) ............................ 15 Figure 1.4. SFRES Geospatial data (Fordcenter $>$ Quaternary_Geology (MapServer)) (ArcGIS REST Services Directory Interface of The SFRES Geospatial Data)............ 17 Figure 1.5. SFRES geospatial data (Fordcenter/Quaternary_Geology (MapServer)) shown with ArcGIS JavaScript (ArcGIS REST Services Directory Interface of The SFRES Geospatial Data).

Figure 1.6. SFRES geospatial data (Fordcenter/Quaternary_Geology (MapServer)) viewed in the ArcGIS Online map viewer (ArcGIS REST Services Directory Interface of The SFRES Geospatial Data).

Figure 1.7. SFRES geospatial data (Fordcenter/Quaternary_Geology (MapServer)) viewed footprint in ArcGIS online map viewer (ArcGIS REST Services Directory Interface of The SFRES Geospatial Data).

Figure 1.8. SFRES geospatial data (Fordcenter/Quaternary_Geology (MapServer)) Legend (ArcGIS REST Services Directory Interface of The SFRES Geospatial Data). 22 Figure 1.9. SFRES geospatial data (Fordcenter/Quaternary_Geology (MapServer)) - All Layers and Tables - 1(ArcGIS REST Services Directory Interface of The SFRES

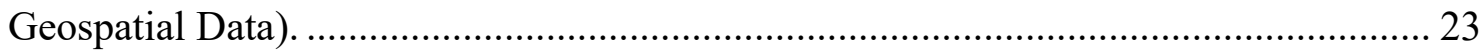

Figure 1.10. SFRES geospatial data (Fordcenter/Quaternary_Geology (MapServer)) All Layers and Tables - 2 (ArcGIS REST Services Directory Interface of The SFRES

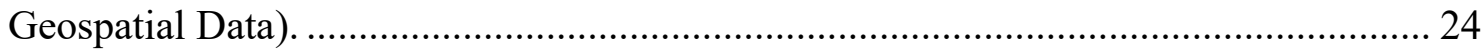
Figure 1.11. SFRES geospatial data (Fordcenter/Quaternary_Geology (MapServer)) Dynamic legend (ArcGIS REST Services Directory Interface of The SFRES Geospatial

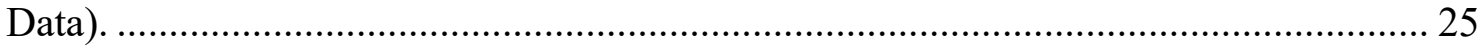

Figure 1.12. SFRES geospatial data (Fordcenter/Quaternary_Geology (MapServer)) Dynamic all layers (ArcGIS REST Services Directory Interface of The SFRES Geospatial Data). 25

Figure 1.13. SFRES geospatial data (Fordcenter/Quaternary_Geology (MapServer)) Description 1 (ArcGIS REST Services Directory Interface of The SFRES Geospatial Data). 
Figure 1.14. SFRES geospatial data (Fordcenter/Quaternary_Geology (MapServer)) Description 2 (ArcGIS REST Services Directory Interface of The SFRES Geospatial Data).

Figure 2.1. Producing maps with ArcGIS API for JavaScript $\odot 2005$ by Manning Publications Co (Rubalcava, ArcGIS Web Development 2015).

Figure 2.2. ArcGIS Server provides access to GIS data such as different base maps (Interface of the application created by author). 35

Figure 2.3. Adding a hillshade (Interface of the application created by author)............ 37

Figure 2.4. Adding Feature Layer (Interface of the application created by author)....... 39

Figure 2.5. Map View Example1 (Interface of the application created by author)....... 41

Figure 2.6. Map View Example2(Interface of the application created by author)........ 41

Figure 2.7. Search, zoom in and zoom out widget (Interface of the application created by author). 43

Figure 2.8. Search widget (Michigan, USA) (Interface of the application created by author).

Figure 2.9. Search widget (Michigan, USA) (Interface of the application created by author)

Figure 2.10. Legend (Interface of the application created by author). .......................... 46

Figure 2.11. An example of legend (Interface of the application created by author).... 46 Figure 2.12. The application with Google Chrome (Interface of the application created by author). 48

Figure 2.13. The application with Internet Explorer (Interface of the application created by author). 49

Figure 2.14. The application with Mozilla (Interface of the application created by author) 50

Figure 3.1. Website overall display (Interface of the application created by author). ... 53 Figure 3.2. SFRES geospatial data tree (Interface of the application created by author).

Figure 3.3. SFRES geospatial data tree (checked one) (Interface of the application created by author). 55

Figure 3.4. SFRES geospatial data tree (downloaded one) (Interface of the application created by author). 56 Figure 3.5. Website overall display with street map (Interface of the application created by author). 57

Figure 3.6. Website overall display with satellite map (Interface of the application created by author). 58

Figure 3.7. Website overall display with hybrid map (Interface of the application created by author).

Figure 3.8. Website overall display with topo map (Interface of the application created

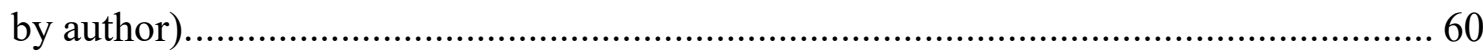

Figure 3.9. Basic map types (Interface of the application created by author)................ 61 
Figure 3.10. Basic map types (chosen streets) (Interface of the application created by author)

Figure 3.11. Search widget (top), and zoom in and zoom out button (Interface of the application created by author).

Figure 3.12. Export - Layout (Interface of the application created by author).............. 63

Figure 3.13. Export - Layout - Advanced Options (Interface of the application created

by author)

Figure 3.14. Export - Map Only (Interface of the application created by author). ........ 64 Figure 3.15. Example of a cartographic correct map layout ready to be exported and printed if desired (Displaying an exported map from the application created by author).

Figure 3.16. An example of map only display (Displaying an exported map from the application created by author). application created by author).... 


\section{List of Tables}

Table 2.1. Date residing on the SFRES geospatial data server. ..................................... 30

Table 2.2. Property overview (ESRI, Developers ArcGIS, Map View 2017)............... 40 


\section{Acknowledgements}

I would like to express my special appreciation to my advisor, Prof. Dr. Ann Maclean for her support, guidance and encouragement throughout my study. I would also like to express my appreciation to Mike Hyslop and Prof. Dr. Bob Maatta. They have spent numerous hours for helping me develop the web mapping application. I also would like to thanks to Dr. Curtis Edson for being on my committee.

I would like to thank General Directorate of State Hydraulic Works for their financial support during my graduate education.

I appreciate Hasan Salih Kulunk and my numerous friends who have supported me throughout this process.

Above all, my biggest gratitude goes to my family for their love, support, patience, and encouragement. I cannot express how grateful I am to have them, my brother Musa Nehir Sozen, my sisters Gulbahar Afsar and Nurhuda Sozen, my mother Pembe Sozen, my father Izzettin Sozen, my uncle Mehmet Mansur Oztasci, my brother-in-law Yusuf Afsar, my nephew Ali Haydar Afsar and my nieces Melis Erten and Ayse Mina Afsar.

Finally, I would like to thank my government for giving me the opportunity to complete a Master's in USA. 


$\begin{array}{ll}\text { Abbreviations } & \\ \text { API } & \text { Application programming interface } \\ C D L & \text { Cropland data layer } \\ C H M & \text { Canopy height model } \\ C S S & \text { Cascading style sheets } \\ D B M S & \text { Database management system } \\ D E M & \text { Digital elevation models } \\ E S R I & \text { Environmental systems research institute } \\ G C P & \text { Ground control points } \\ G D B & \text { Geodatabase } \\ G I S & \text { Geographic information system } \\ H T M L & \text { Hypertext markup language } \\ M D O W & \text { Multi-directional oblique weighted } \\ R E S T & \text { Representational state transfer } \\ S D K & \text { Software development kit } \\ S F R E S & \text { School of forest resources and environmental science } \\ S Q L & \text { Strured Query Language } \\ U R L & \end{array}$




\begin{abstract}
This thesis emphasizes current Web GIS technologies with emphasis on architectures, particularly web applications. The goal of the study is based on data sharing and improving the efficiency of students, professionals and researchers utilizing data from the School of Forest Resources and Environmental Science (SFRES) geospatial data.

This paper is an overview of the MTU geospatial web page and using ArcGIS JavaScript API to develop a web application. The development of the application was based on open source software tools such as Map Server and Feature Server for the GIS functions, HTML, and JavaScript as programming languages and CSS as a markup language.
\end{abstract}




\section{Chapter - Introduction}

\subsection{Importance of GIS}

A Geographic Information System (GIS) is a computer-based technology designed for analyzing, managing, storing, and displaying geospatial data (Chang 2014). GIS allows us to view, understand, question, interpret, and visualize our world in ways that reveal relationships, patterns, and trends in the form of maps, globes, reports, and charts. Geographic analysis is the core strength of GIS. Depending on the project, there are many different analysis approaches to choose from. GIS modeling tools make it relatively easy to conduct simple or complex analyses and create new output.

As Chang (2014) mentioned, GIS has the capability to store, manipulate and display geospatial data on computer systems. Once the data is collected, edited and referenced to a projected coordinate system, the next step is to make the data readily available to users for making maps, assisting in fieldwork and conducting spatial analyses. The main goal of this research was to develop an application programming interface (API) to facilitate access to the geospatial data found on the School of Forest Resources and Environmental Sciences (SFRES) GIS server. The mapping application enables students and researchers to access the data from anywhere and anytime without having direct access to the GIS server. The web application uses the National Map Viewer format and includes a scale bar, north arrow, legend, title and map author. The created map view can be downloaded and/or printed for field use and other applications. 


\subsection{Web GIS Technology}

Web GIS, the integration product of Web Technologies and GIS, is different from traditional GIS in that it masks the differences among various types of databases, networks, hardware and software (Lu, et al. 2010). It is a platform for delivering GIS capabilities and many organizations shares and collaborates GIS resources over the internet to access easily and use geographic information in recent years (Law 2013). Therefore, Web GIS provides accessible, manageable and sharable global geographic information data indiscriminatingly (Liu, et al. 2009).

Geospatial data can be acquired via web GIS from the internet (Peng and Tsou 2003). According to the research by Menno-Jan (2004), although Web GIS offers GIS functionality in a web environment, Web GIS is used in limited access situations for mapping applications to solve geospatial analysis problems (Kraak 2004). The interactive and dynamic appearance of maps will guide and assist users as a future trend in solving geospatial analysis problems (Kraak 2004).

Web GIS Applications are created and designed using a wide variety of resources. A web GIS includes at least a server and a client (ESRI, Developers ArcGIS, Create Web Apps 2017). The client is a mobile application, desktop application or web browser and the server is a GIS server (ESRI, Developers ArcGIS, Create Web Apps 2017). The foundation for all ArcGIS web APIs is the ArcGIS Server REST (REpresentational State Transfer) API and a web application based on ArcGIS technology is built by ArcGIS API for Flex, ArcGIS API for Silverlight, ArcGIS API for JavaScript and others (Rubalcava, ArcGIS Web Development 2015). ArcGIS API for Silverlight and ArcGIS API for Flex use Microsoft Silverlight to build applications, and provide fluid and interactive applications. The Flex API based on the Flex software development kit (SDK) and this API was released in 2014 (Svensson 2014). ArcGIS API for Silverlight and ArcGIS API for Flex were supported through 2016, and followed by ESRI leading customers to explore web solutions based on ArcGIS API for JavaScript (Hansen and Zwaap 2015). 
ArcGIS JavaScript API is the only API that does not require a browser plug-in and supports the following browsers:

- Chrome

- Firefox

- Safari

- Microsoft Edge

- Internet Explorer 11+ (Rubalcava, ArcGIS Web Development 2015).

Consequently, the API developed for accessing the SFRES GIS server is built with ArcGIS API for JavaScript. This program is a client-server side scripting language and provides interactive applications. JavaScript facilitates web page functionality and minimizes differences between any browsers.

\subsection{Database Design and Construction}

Designing a geodatabase (GDB) is based upon a common set of fundamental GIS design steps and requires forethought and planning. Consideration must be given to users' needs and their level of expertise in accessing and manipulating geospatial data as well as how to present the results to various users. Geospatial data stored in a GDB is managed in a standardized Data Base Management System (DBMS) tables using SQL data types, which allows SQL statements to search the GDB (Arctur and Zeiler 2004). There are geographical and topological relationships for all GDB spatial entities. To manage data within the GIS database, PostgreSQL is generally used, and it is an open source Database software (Xulin, Wenfang and Guohong 2008).

ArcGIS Server is used to publish services for visualization, spatial data management and spatial analysis (Esri, ArcGIS for Developers, ArcGIS Server services overview 2017). The REST API offers additional information on using ArcGIS Server Services successfully (ESRI, Developers ArcGIS, Web App Builder for ArcGIS (Developer 
Edition) 2017). This API includes several sections to work with different components of the ArcGIS system (Esri, ArcGIS Resources, The ArcGIS REST API 2017). ArcGIS REST API can utilize ArcGIS Online services hosted by Esri and services (Esri, ArcGIS Resources, The ArcGIS REST API 2017). By using the ArcGIS REST API, web services can be published and items can be created, and shared on ArcGIS Online or an in house portal (Esri, ArcGIS Resources, The ArcGIS REST API 2017).

ArcGIS Server site can be operated with a single machine (Figure 1.1), or multiple machines (Figure 1.2). The single ArcGIS Server machine is configured with using a local account or the domain account designate as the ArcGIS Server account (ESRI, ArcGIS Enterprise, Installation Guides, Single-machine deployment 2017, ESRI, ArcGIS Server, The ArcGIS Server Account 2017). More than one ArcGIS Server machines can be administered and used as a single logical unit in multiple machine (ESRI, ArcGIS Enterprise, Installation Guides, Multiple-machine deployment with ArcGIS Web Adaptor 2017).

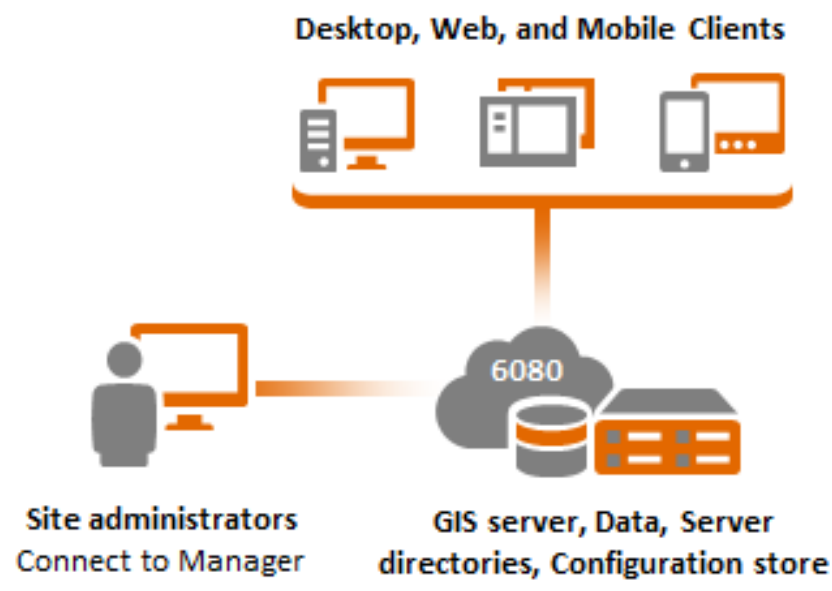

Figure 1.1. Architecture of A Single ArcGIS Server Machine (C) 2017 Esri (ESRI, ArcGIS Enterprise, Installation Guides, Single-machine deployment 2017). 


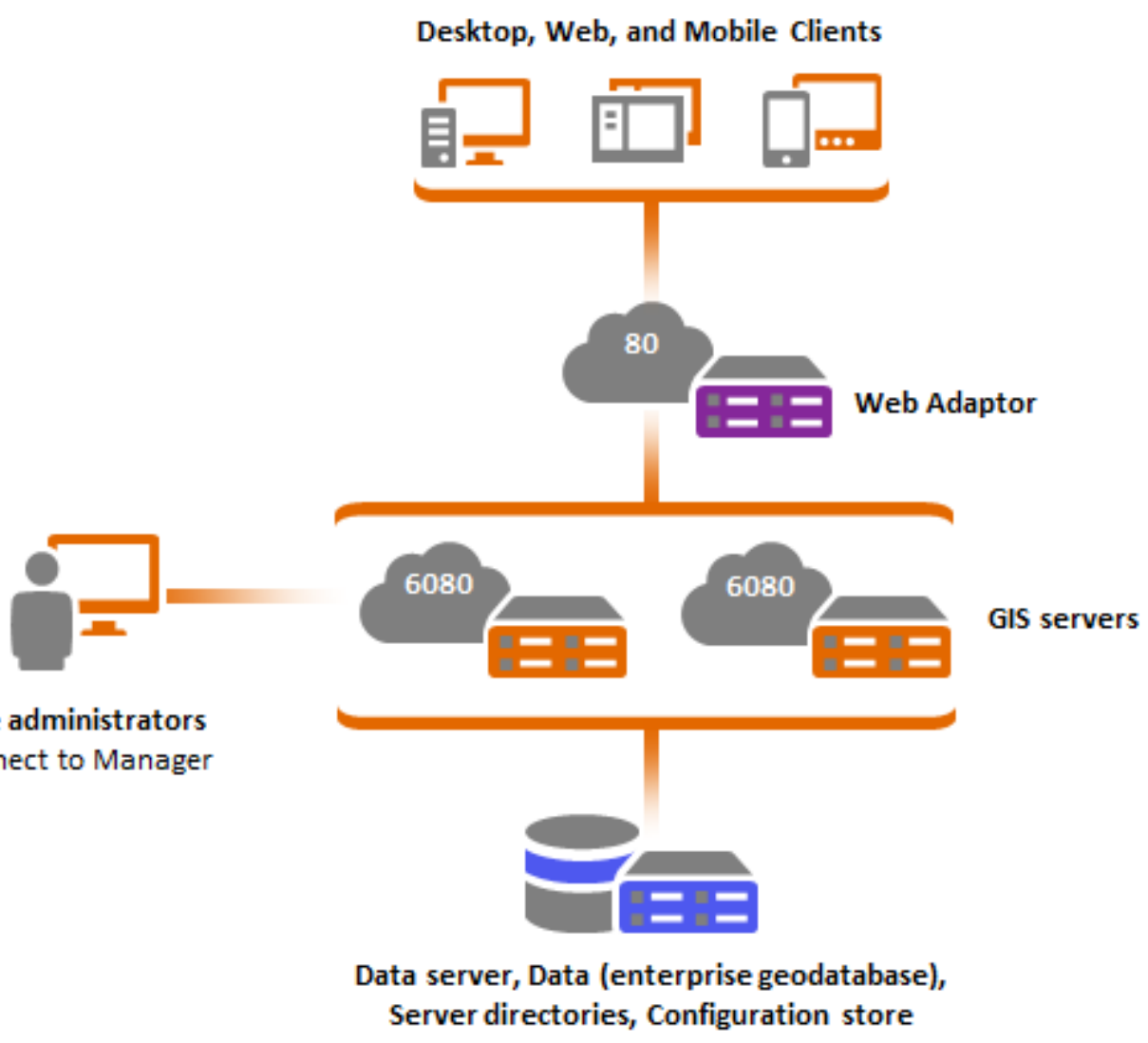

Figure 1.2. Architecture of Multiple ArcGIS Servers in Multiple-Machine (C) 2017 Esri (ESRI, ArcGIS Enterprise, Installation Guides, Multiple-machine deployment with ArcGIS Web Adaptor 2017).

ArcGIS Server uses port 6080 to communicate with machines on the internet, and the firewall must be allowed HTTP communication through this port (ESRI, ArcGIS Enterprise, Installation Guides, Ports used by ArcGIS Server 2017). Also after installing ArcGIS for Server, it can be administered it by making web service requests and connecting immediately through port 6080 (Law, Understanding architecture, deployment, and workflows 2013). As shown on Figure 1.2, ArcGIS Server clients connect to the Web Adaptor before connecting the ArcGIS Servers. This makes the overall site more resilient to failures and provides security features (ESRI, ArcGIS 
Enterprise, Installation Guides, Multiple-machine deployment with ArcGIS Web Adaptor 2017).

In this research, a single ArcGIS Server machine was used because it permits high performance and is straightforward to install, maintain and upgrade. Additionally, additional components are not needed. The ArcGIS Server site provides GIS resources as a web service that create a link via REST-based architecture (Law, Understanding architecture, deployment, and workflows 2013). All SFRES Geospatial data are available from the website (Figure 1.3).

Here is the link: <http://impute.ffr.mtu.edu:6080/arcgis/rest/services/Fordcenter> 


\begin{tabular}{|c|c|}
\hline - Folder: Fordcenter $\times+$ & -0 \\
\hline$\leftarrow \rightarrow \circlearrowright \quad \mid$ imputeffit.mtu.edu.6080/arcois/rest/services/Fordcenter & (10) 经 \\
\hline ArcGIS REST Services Directory & Looin I Get Token \\
\hline Home > services > Fordcenter & Help | API Reference \\
\hline
\end{tabular}

Help I API Reference

\section{Folder: Fordcenter}

Current version: 10.31

View Footprints In: ArcGIS Online map viewer

Services:

- Fordcenter/All roads MI (MapServer)

- Fordcenter/bedrock geology (MapServer)

- Fordcenter/Counties MI (MapServer)

- Fordcenter//lacial Landforms UP (MapServer)

- Fordcenter/lidar hilishade (MapServer)

- Fordcenter/property boundaries (Mapserver)

- Fordcenter/Quaternary Geology (MapServer)

- Fordcenter/Sections MI (MapServer)

- Fordcenter/SSURGO soils (MapServer)

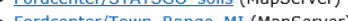

- Fordcenter/TRS MI (MapServer)

$\bar{u}$

Supported Interfaces: REST SOAP Sitemap Geo Sitemap

Figure 1.3. SFRES Geospatial Data - ArcGIS for Server main access point (ArcGIS REST Services Directory Interface of The SFRES Geospatial Data). 
As shown in Figure 1.3, SFRES geospatial data display in the Ford Center folder on site. Figure 1.4 shows the selection of, "Fordcenter > Quaternary_Geology (MapServer)" was selected and these is metadata which includes information about the data (Figure 1.4). The layer can be viewed in ArcGIS JavaScript (Figure 1.5) and ArcGIS Online map viewer (Figure 1.6). The layer can be downloaded as a .kmz file by clicking Google Earth, as a .lyr file by clicking ArcMap and as a .nmf file by clicking ArcGIS Explorer. The layer also can be viewed in the ArcGIS Online map viewer and the tag shows the center of the area (Figure 1.7). 
- Fordcenter/Quatermary. $x+$

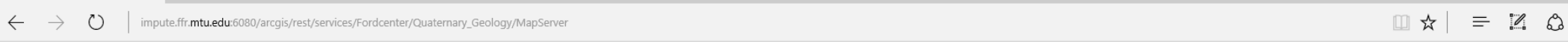

ArcGIS REST Services Directory

Home > services > Fordcenter > Quaternary Geology (MapServer)

JSON1 ISOAPI WNTIS

Fordcenter/Quaternary_Geology (MapServer)

view In: ArcGIS Javascript ArcGIS Online map viewer Google Earth ArcMap ArcGIS Explorer

View Footprint In: ArcGIS Online map viewer

Service Description: State of Michigan quaternary (glacial) landforms

Map Name: Layers

Legend

All Layers and Tables

Dynamic Legend

Dynamic All Layers

Layers:

- fordcenter.sfres.Quaternary Geology features MI (0)

- fordcenter.sfres. Quaternary Geology MI (1)

च

Copyright Text: $U$ of Michigan

Spatial Reference: 26916 (26916)

Single Fused Map Cache: true

Figure 1.4. SFRES Geospatial data (Fordcenter > Quaternary_Geology (MapServer)) (ArcGIS REST Services Directory Interface of The SFRES Geospatial Data). 


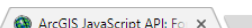

Ayean $-0 \times$

ArcGIS JavaScript API: Fordcenter/Quaternary_Geology

te using the ArcGIS Javascript API

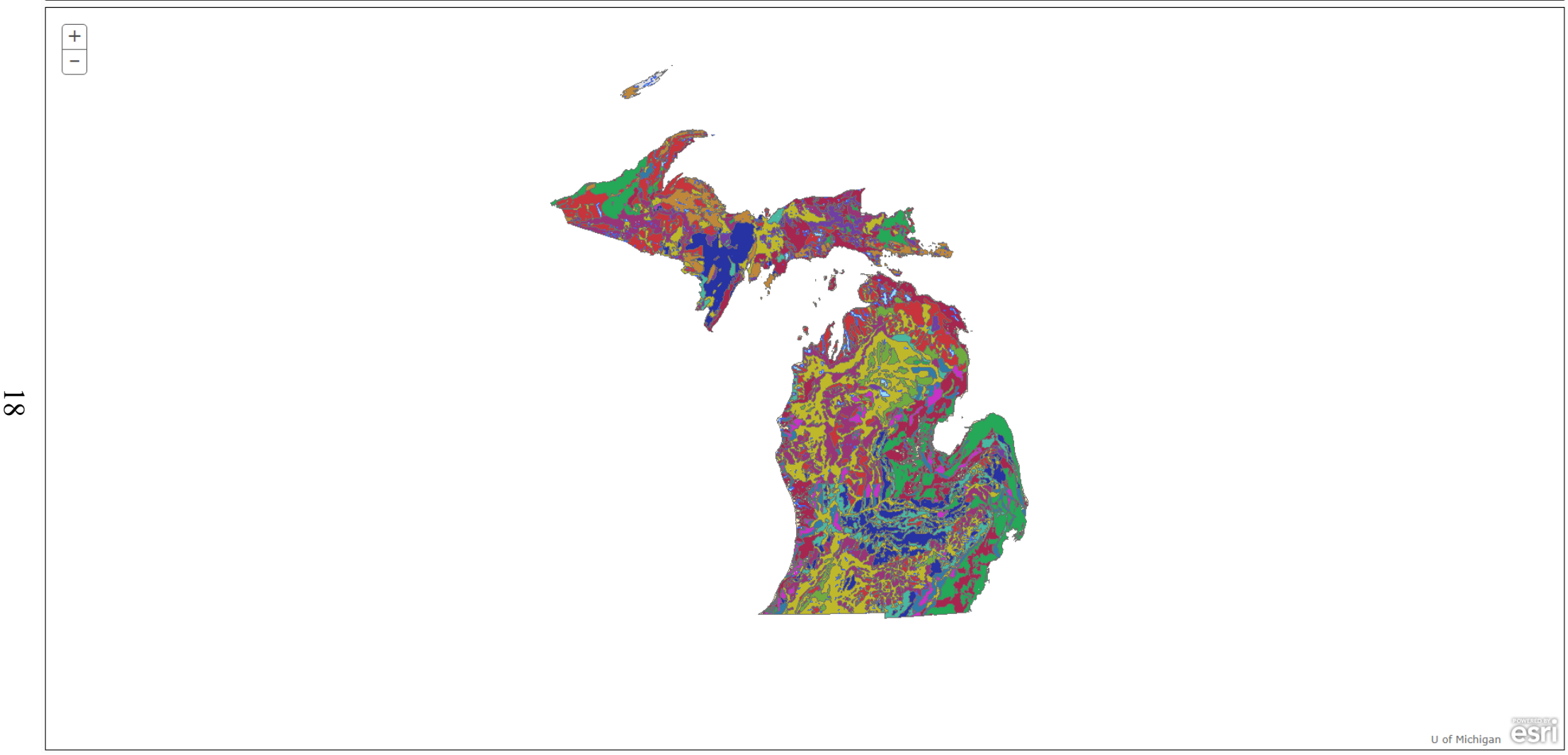

Figure 1.5. SFRES geospatial data (Fordcenter/Quaternary_Geology (MapServer)) - shown with ArcGIS JavaScript (ArcGIS REST Services Directory Interface of The SFRES Geospatial Data). 


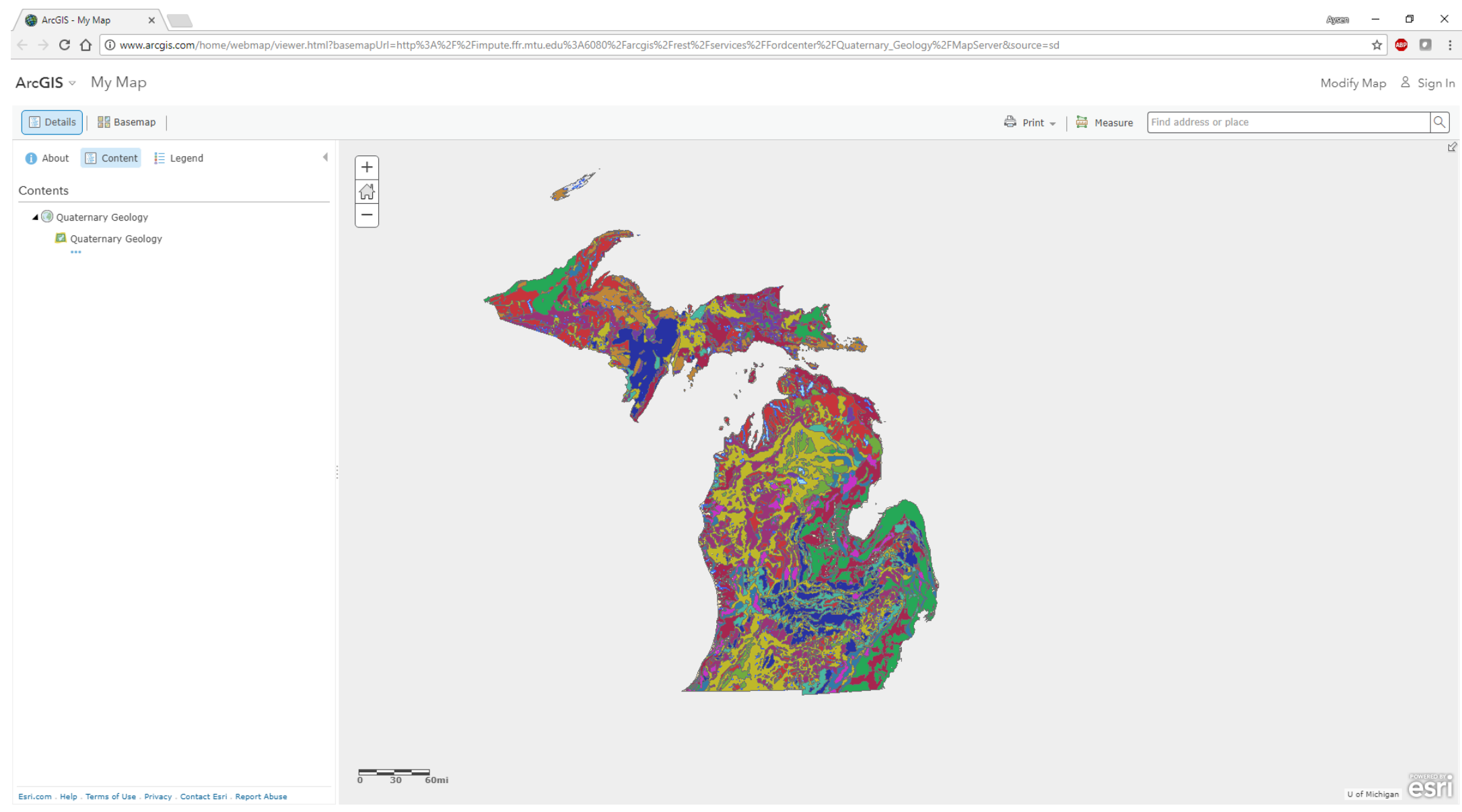

Figure 1.6. SFRES geospatial data (Fordcenter/Quaternary_Geology (MapServer)) - viewed in the ArcGIS Online map viewer (ArcGIS REST Services Directory Interface of The SFRES Geospatial Data). 


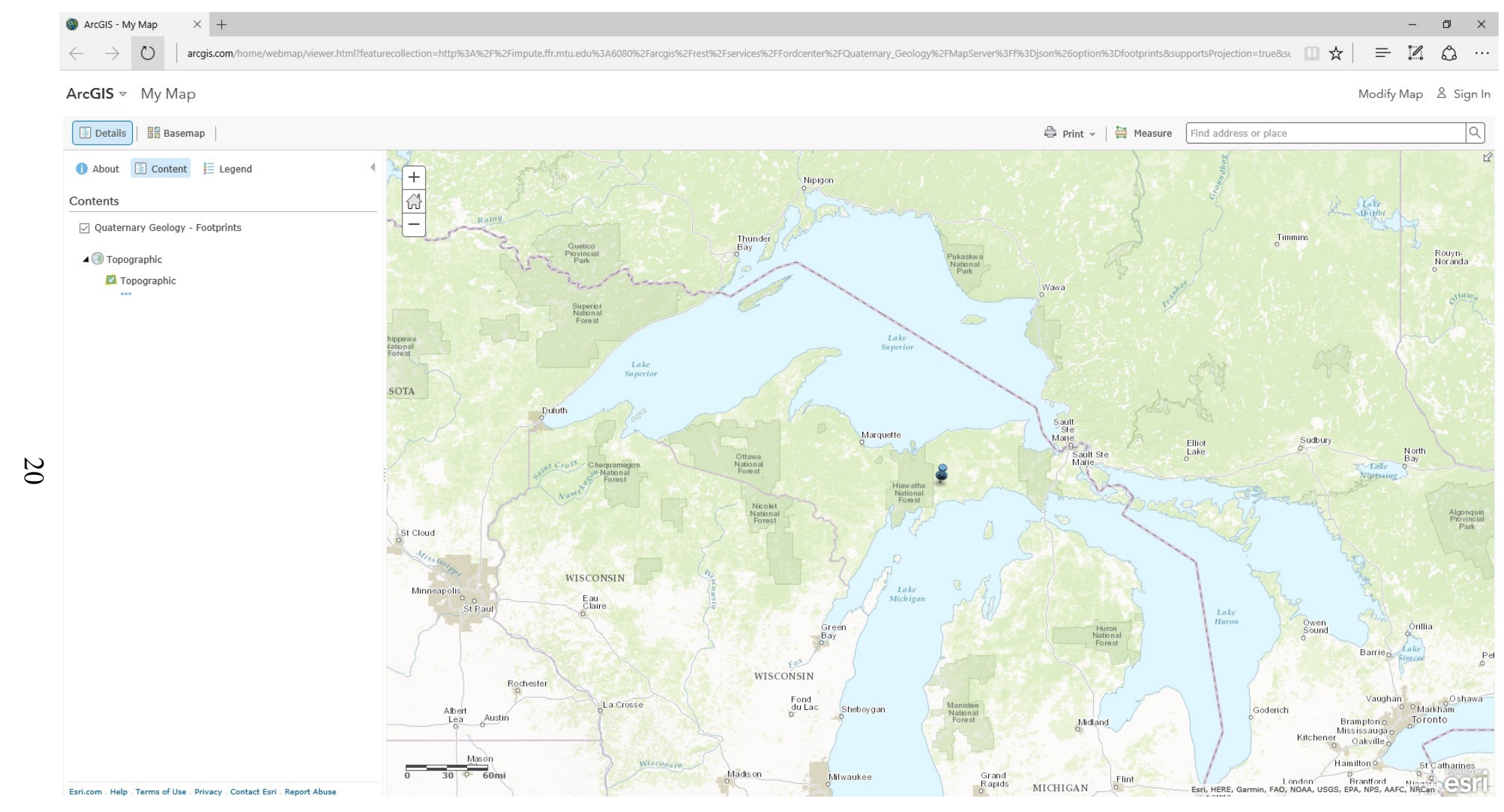

Figure 1.7. SFRES geospatial data (Fordcenter/Quaternary_Geology (MapServer)) - viewed footprint in ArcGIS online map viewer (ArcGIS REST Services Directory Interface of The SFRES Geospatial Data). 
Legend of the layer can be displayed by clicking "Legend" button on the site (Figure 1.8). It can be seen all information about layers and tables by clicking the "All Layers and Tables" button (Figure 1.9. and Figure 1.10.). "Dynamic Legend" and/or "Dynamic All Layers" represent layers and/or tables of a map service published the server and they based on an existing map service layer (ESRI, ArcGIS-Resources-Dynamic Layer/ Table n.d.) (Figures 1.11 and 1.12). It includes initial and full extent (xmin, ymin, xmax, ymax, spatial reference), and document information. 
Figure 1.8. SFRES geospatial data (Fordcenter/Quaternary_Geology (MapServer)) - Legend (ArcGIS REST Services Directory Interface of The SFRES Geospatial Data). 


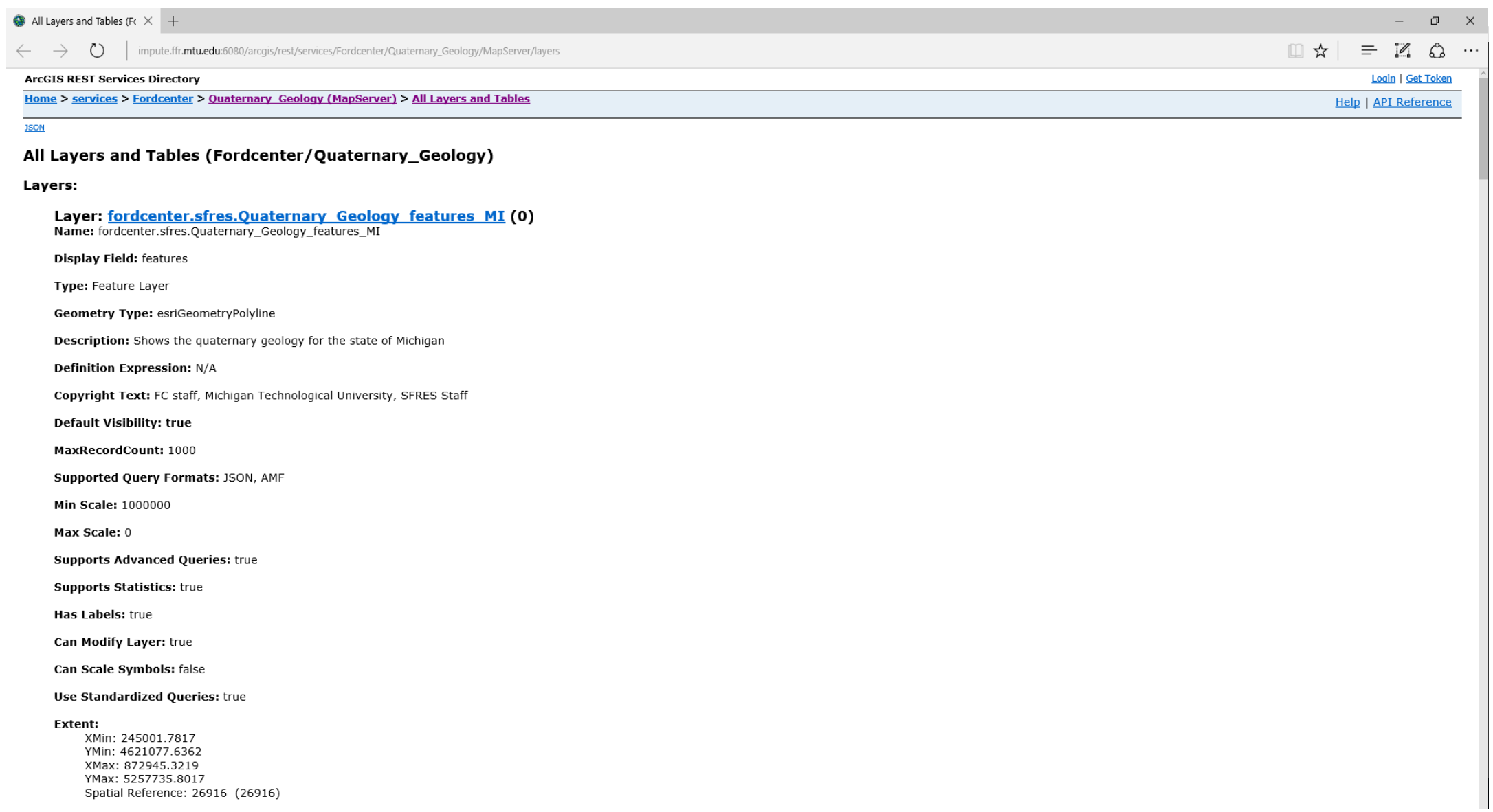

Figure 1.9. SFRES geospatial data (Fordcenter/Quaternary_Geology (MapServer)) - All Layers and Tables - 1(ArcGIS REST Services Directory Interface of The SFRES Geospatial Data). 


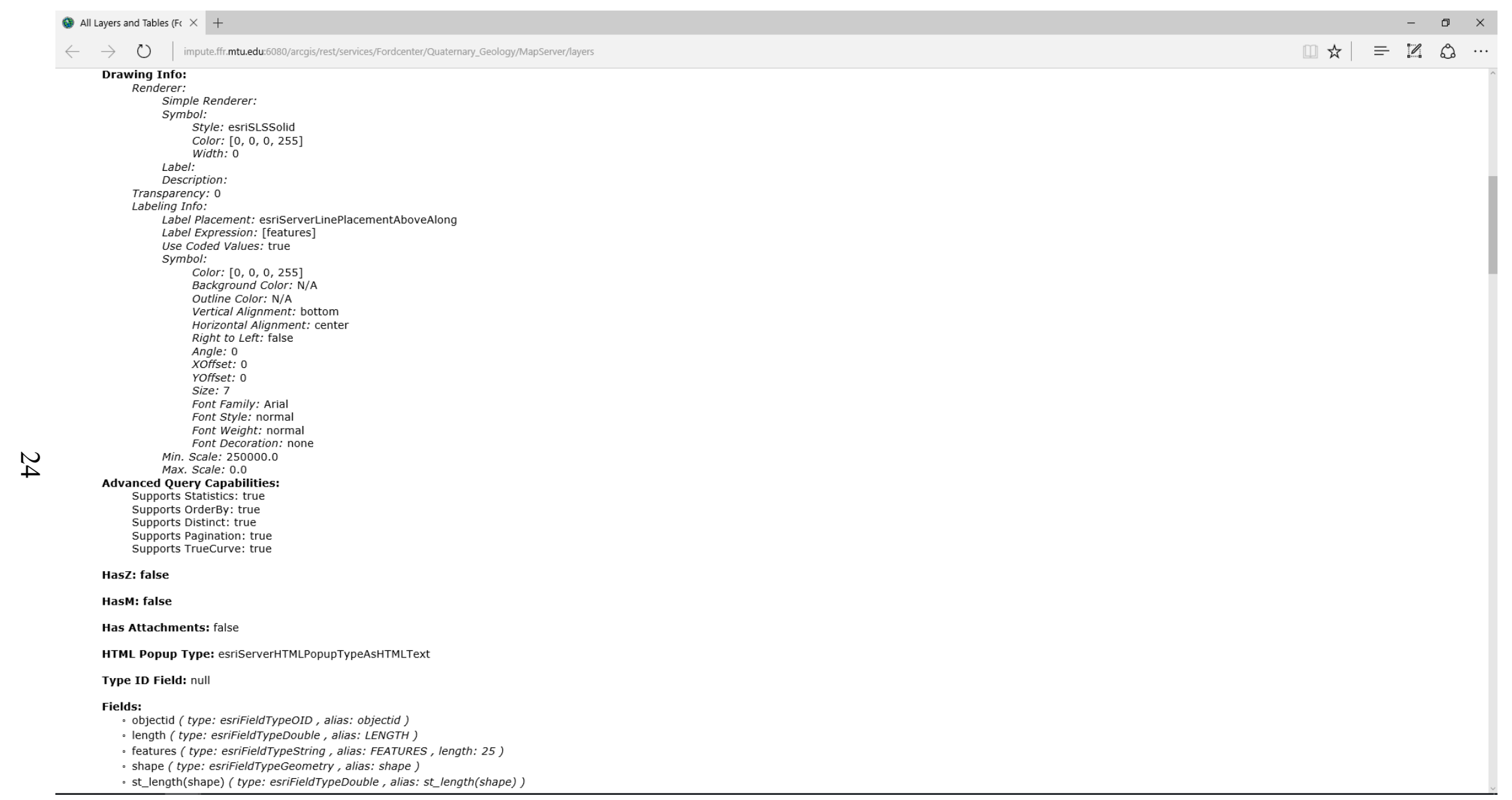

Figure 1.10. SFRES geospatial data (Fordcenter/Quaternary_Geology (MapServer)) - All Layers and Tables - 2 (ArcGIS REST Services Directory Interface of The SFRES Geospatial Data). 


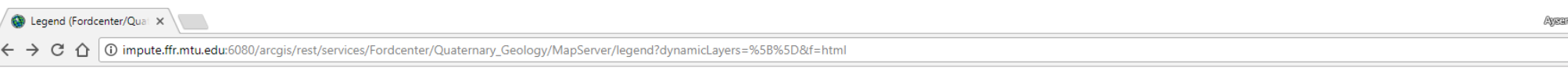

Legend (Fordcenter/Quaternary_Geology)

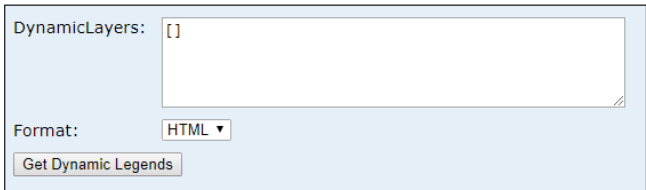

Figure 1.11. SFRES geospatial data (Fordcenter/Quaternary Geology (MapServer)) - Dynamic legend (ArcGIS REST Services Directory Interface of The SFRES Geospatial Data)

N

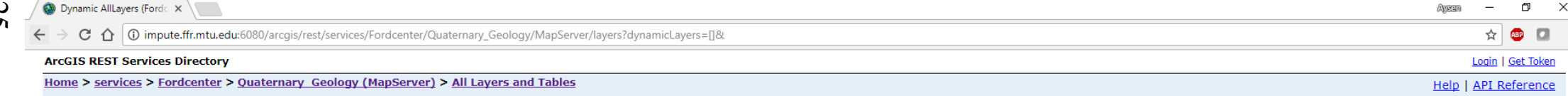

Figure 1.12. SFRES geospatial data (Fordcenter/Quaternary_Geology (MapServer)) - Dynamic all layers (ArcGIS REST Services Directory Interface of The SFRES Geospatial Data). 


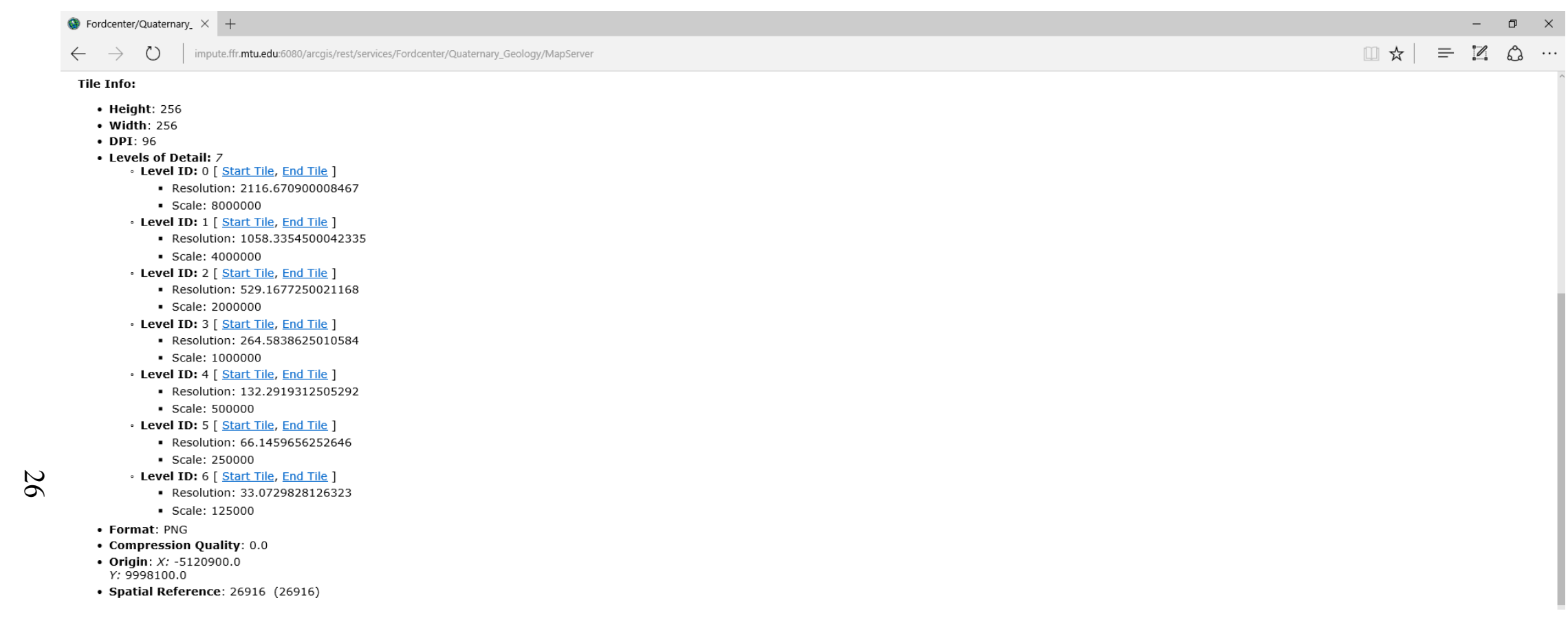

Figure 1.13. SFRES geospatial data (Fordcenter/Quaternary_Geology (MapServer)) - Description 1 (ArcGIS REST Services Directory Interface of The SFRES Geospatial Data). 
- Fordcenter/Quaternary. $x+$

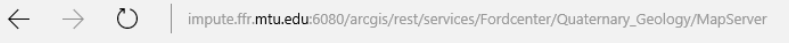

- Spatial Reference: 26916 (26916)

Initial Extent:

XMin: 129813.76767575386

YMax: 981888.33872424111

YMax: 5379940.912685001
Spatial Reference: $26916(26916)$

Full Extent:

XMin: 238106.018
YMin: 4618363.229

XMax: 873596.0884

YMax: 5343675.3087
Spatial Reference: 26916 (26916)

Units: esrimeters

Supported Image Format Types: PNG32,PNG24,PNG,JPG,DIB,TIFF,EMF,PS,PDF,GIF,SVG,SVGZ,BMP

Document Info:

$$
\begin{aligned}
& \text { Title: } \\
& \text { Author: }
\end{aligned}
$$

Author:
Comments: State of Michigan boundary

N

Subject: State of Michigan boundary
Category:

Keywords: Michigan, quaternary
Antialiasingmode: None

AntialiasingMode: None
TextAntialiasing Mode:

Supports Dynamic Layers: true

MaxRecordCount: 1000

MaxImageHeight: 4096

MaxImageWidth: 4096

Supported Query Formats: JSON, AMF

Min Scale: 8000000

Max Scale: 125000

Child Resources: Info Dynamic Layer

Supported Operations: Export Map Identify Find Return Updates Generate KML

Figure 1.14. SFRES geospatial data (Fordcenter/Quaternary_Geology (MapServer)) - Description 2 (ArcGIS REST Services Directory Interface of The SFRES Geospatial Data). 
After adding a single machine to the site when working with ArcGIS 10.31 for Server, and adding all SFRES geospatial data to the site, information can be requested by structuring a request URLs (Uniform Resource Locator), which is in a defined format from the server to display on web application (Law 2013). The URL returns a web page, an image, or another form of data (Rubalcava, ArcGIS Web Development 2015). Observe the URL bar to perceive how different URLs are used to recover data through REST while navigating the Service Directory (Law, Understanding architecture, deployment, and workflows 2013). 


\section{Chapter - Software and Data}

One of the most important steps involved in creating a web application is deciding how it will be organized and what content will be included. (Winkelman 2004).

Web applications consist of three components:

- The database

- The "server" is a web application server at remote location anywhere in the world. It scripts before the HTML is loaded. That will process web requests and send pages to the client and the action takes place on a web server (Segue 2013).

- The client runs in a web browser like Explorer, or Google Chrome and process requests without call - backs to the server (Wodehouse 2015).

The purpose of this work ensures a powerful and efficient application. Therefore, the web application can be in interaction with the user via ArcGIS API for JavaScript, the HTML viewer developed for the user interface and the CSS formatted the HTML document. The client-side of the system runs JavaScript beside HTML (Basu and Paul 2016). It is for displaying the map and implementing the processing in the server-side, then regaining the results (Basu and Paul 2016).

\subsection{Data Set}

The data is stored and managed in a PostgreSQL object-relational database, and the data served out via ArcGIS REST services such as the Map Server and Feature Server services. There are three basic geospatial data types (tables, feature classes, and raster datasets) inside the GDB. The geographic dataset is designed as a logical data model within the GDB structure. The SFRES GDB utilizes the map model developed for the National Map Viewer and includes elevation, hydrography, boundaries, transportation, structures, land cover, etc (Table 2.1.). 
Table 2.1. Date residing on the SFRES geospatial data server.

\begin{tabular}{|c|c|}
\hline Data Type & Name \\
\hline SDE Feature Class & Boundaries/City \\
\hline SDE Feature Class & Boundaries/County \\
\hline SDE Feature Class & Boundaries/First Division \\
\hline SDE Feature Class & Boundaries/Special Survey \\
\hline SDE Feature Class & Boundaries/Townships \\
\hline SDE Feature Class & Boundaries/School Properties \\
\hline SDE Feature Class & Boundaries/State Outlines \\
\hline SDE Feature Class & Boundaries/Topo Grid \\
\hline SDE Feature Class & Boundaries/Upper Peninsula \\
\hline SDE Feature Class & Boundaries/Village \\
\hline SDE Feature Class & Control Points \\
\hline SDE Feature Class & Control Points/GCP (Ground Control Points)Section Corners \\
\hline SDE Feature Class & Control Points/Lidar Control Polygon \\
\hline SDE Feature Class & Geomorphology/Bedrock Geology \\
\hline SDE Feature Class & Geomorphology/Michigan Soils \\
\hline SDE Feature Class & Geomorphology/Quaternary Geology Features MI \\
\hline SDE Feature Class & Geomorphology/Quaternary Glacial Landforms UP \\
\hline SDE Feature Class & Geomorphology/Quaternary Glacial Landforms UP1 \\
\hline SDE Feature Class & Geomorphology/Western UP Contours 50M \\
\hline SDE Feature Class & Hydrography/Lakes and Ponds \\
\hline SDE Feature Class & Hydrography/Rivers and Streams \\
\hline SDE Feature Class & Hydrography/Watersheds UP \\
\hline SDE Feature Class & Hydrography/Wells \\
\hline SDE Feature Class & Infrastructure/All Buildings \\
\hline SDE Feature Class & Land Use/Michigan 1800 Land use \\
\hline SDE Feature Class & Roads Trails/Alb Town roads \\
\hline SDE Feature Class & Roads Trails/All roads \\
\hline
\end{tabular}




\begin{tabular}{|l|l|}
\hline SDE Feature Class & Roads Trails/St roads \\
\hline SDE Feature Class & Roads Trails/Trails \\
\hline SDE Feature Class & SSurgo Soils/Soils \\
\hline SDE Raster & CDL2013 (Cropland Data Layer) \\
\hline SDE Raster & Ford Lands Aspect \\
\hline SDE Raster & $\begin{array}{l}\text { Ford Lands MDOW (Multi-Directional Oblique Weighted) } \\
\text { Hillshade }\end{array}$ \\
\hline SDE Raster & Ford Lands Slope \\
\hline SDE Raster & Keweenaw Imagery \\
\hline SDE Raster & Lidar CHM (Canopy Height Model) \\
\hline SDE Raster & Lidar CHM Hillshade \\
\hline SDE Raster & Lidar DEM (Digital Elevation Models) \\
\hline SDE Raster & Lidar Hillshade \\
\hline SDE Raster & Western UP DEM 30M \\
\hline
\end{tabular}

\subsection{Cascading Style Sheet}

Web site developers and users can gain control over a browser's display pages by a Cascading Style Sheet that defines how different page elements appear in the viewer (Paulson 2005). There are three levels of style sheets: external style sheets, internal style sheets, inline sheets and inline style.

External style sheets are in separate files and can be applied to any document. They are capable of changing the look of an entire website. A $<$ link $>$ tag is used to specify that the browser needs to fetch and use a particular external style sheet file as noted in the following example.

$$
<\text { link rel ="stylesheet" type }=\text { "text/css" href }=\text { "externalfile.css" }></ \text { link }>
$$


The "rel" is required for the $<$ link $>$ tag to specify the relationship between the current, and the linked document and "stylesheet" is the value of the "rel" attribute. The "type" attribute specifies the text/css type of the linked document. The "href" attribute is the location of the .css document.

The $<$ style $>$ element defines style information and internal style sheets are used for a single page which has a unique style.

$$
<\text { style type }=" \text { text } / \text { css" }>\ldots .</ \text { style }>
$$

Inline style is specified for a specific occurrence of a tag and appears in the opening tag. It applies only to the content of that tag.

$$
\text { style }=“ \ldots ”
$$

\subsection{JavaScript}

JavaScript is a Hyper Text Markup Language (HTML) programming language used to support web sites and web applications. There are three major parts of JavaScript. The first one is Core JavaScript that consists of the basic JavaScript language, operators, expressions, and statements. The second one is Client Side JavaScript that are statements inserted in an HTML page, and interpreted by the web browser which respond to user events like page navigation.

The last one is Server Side JavaScript that are statements also embedded in an HTML page, and Server Side JavaScript also contains the core JavaScript elements (Oracle 1999). A web application or a web app, client-server software application, uses a combination of client-side scripts to present information to users and server-side scripts to store the information and retrieval of the information (Ndegwa 2016). 


\subsection{ArcGIS JavaScript API}

ArcGIS JavaScript API, a well-stocked JavaScript library, is designed to maximize productivity to build mapping applications (Rubalcava, ArcGIS Web Development 2015). This API is a simple way to insert the GIS maps such as displaying an interactive map of the data, and an ArcGIS Server is needed to deploy applications built with this API (Aly and Labib 2013). Generating hi-performing apps and decent imaging of data requires this API that compounds new web technology and powerful geospatial abilities (APIs 2017).

The ArcGIS JavaScript API combines modern web technology, and it is designed to develop productivity for the best-enhanced web mapping applications and smarter data visualization. The API also combines powerful geospatial abilities enabling us to generate hi-performing apps (ESRI, Developers ArcGIS 2017). ArcGIS API for JavaScript make it easy to interact with ArcGIS Server to provide data-rich web map applications and (Rubalcava, ArcGIS Web Development 2015) (Figure 2.1.).

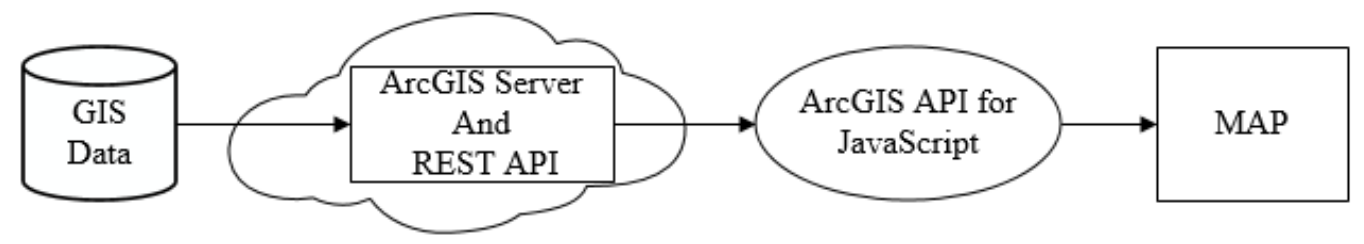

Figure 2.1. Producing maps with ArcGIS API for JavaScript (C) 2005 by Manning Publications Co (Rubalcava, ArcGIS Web Development 2015).

This application consists of the following items:

1 - Map viewer

- Build map viewer for displaying vector maps, ArcGIS JavaScript API used.

- Set base map (e.g. Streets map, Topographic map, ...)

- Navigation toolbar (Zoom in, Zoom out)

- Search toolbar (the ability to search any city, country, etc.)

- Legend widget (to display legend with focusing in layer) 
- $\quad$ Export map (.pdf, .png32, .png8, .jpg, .gif, .eps, .svg, .svgz file format) 2 - Downloading data

- Downloadable data (.lyr file format)

GIS data is generally stored in a GDB on a server and is not directly accessible via the web. ArcGIS server is the gateway for both storing ArcGIS data and viewing GIS it in external clients like a web browser. The ArcGIS API for JavaScript displays map services in the browser (Rubalcava, ArcGIS Web Development 2015). The ArcGIS API for JavaScript is based on Dojo, and the Dojo Toolkit offers many tools for writing JavaScript. Therefore, this application was created with using version 4.3 of the ArcGIS API for JavaScript, and the Dojo toolkit.

\subsubsection{ESRI}

ESRI is the global market leader in GIS and its next generation JavaScript API is the 4.3 series of the ArcGIS API for JavaScript and is used for the SFRES web based mapping application. The following sections provide an overview of some key capabilities of this web application.

\section{Map Application}

The map application provides mapping contexts where users can change the base maps or background maps. Options include topographic, satellite imagery, streets and hybrid maps based on ESRI Base Map geospatial data. The differences between these base maps are shown in Figure 2.2.

require([ "esri/Map"],

function(Map) \{

/* code goes here */

\}); (ESRI, ArcGIS Developers- ArcGIS API for JavaScript - ESRI - Map 2017) The "require" tag imports resource, is "esri/Map", into the web application. 


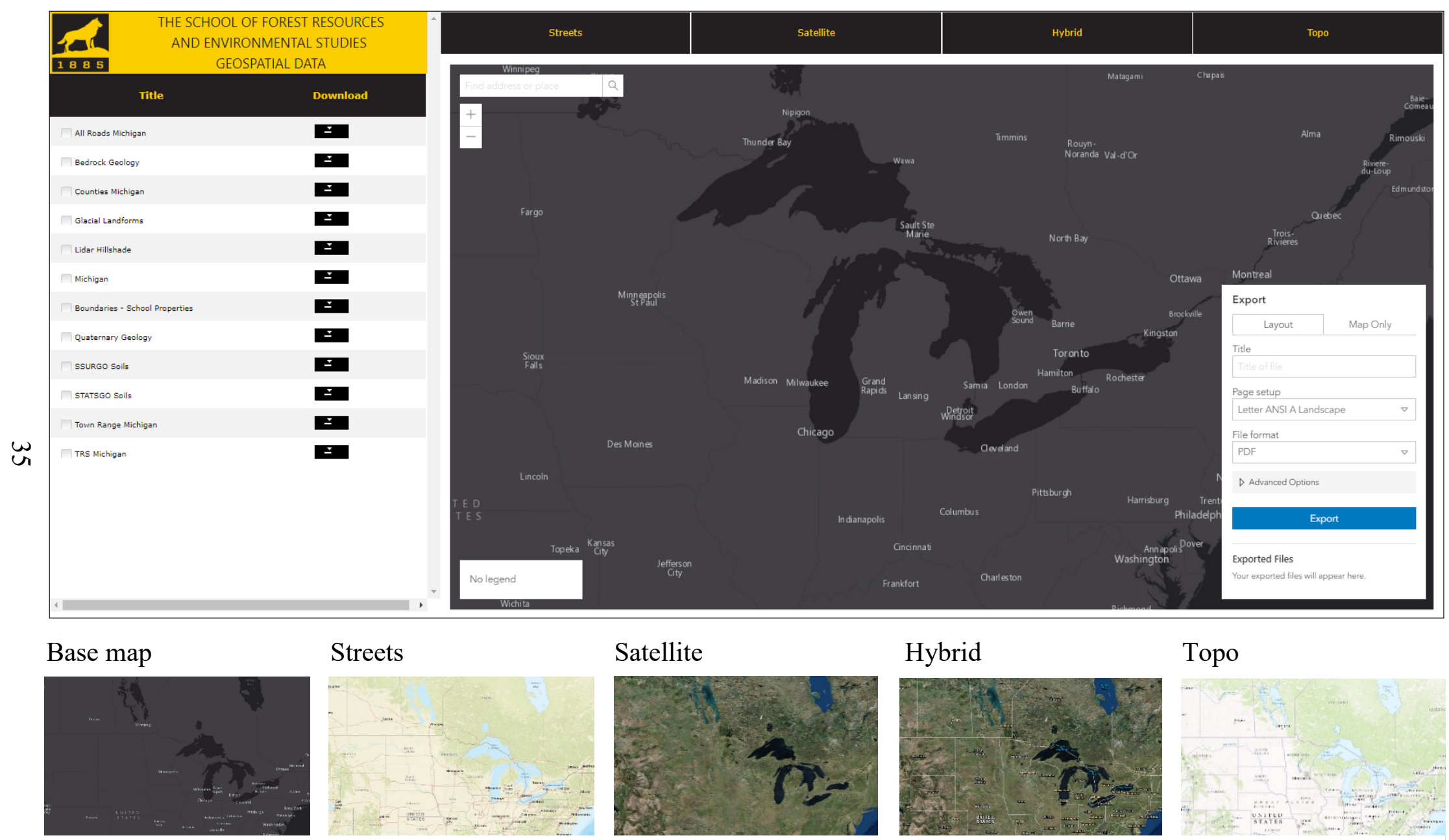

Figure 2.2. ArcGIS Server provides access to GIS data such as different base maps (Interface of the application created by author). 


\section{Layers}

Layer has no constructor and the base class for all layers can be added to a map (ESRI, ArcGIS for Developers - ArcGIS API for JavaScript - Api ReferenceLayer 2017). Different types of GIS layers, such as map image layer, feature layer, etc., can be added to the map using the add method statement.

$$
\text { map.add(Layer); }
$$

\section{- Map Image Layer}

A MapImageLayer represents a resource and it allows the map display to be analyzed dynamically (ESRI, Developers ArcGIS, MapView, Map Image Layer 2017). A map image layer was added with using this tag (Figure 2.3)

require([ "esri/layers/MapImageLayer "],

function(MapImageLayer) \{

var mapimagelayer = new MapImageLayer( $\{$ url: MapImageURL \});

\}); (ESRI, Developers ArcGIS, MapView, Map Image Layer 2017) 


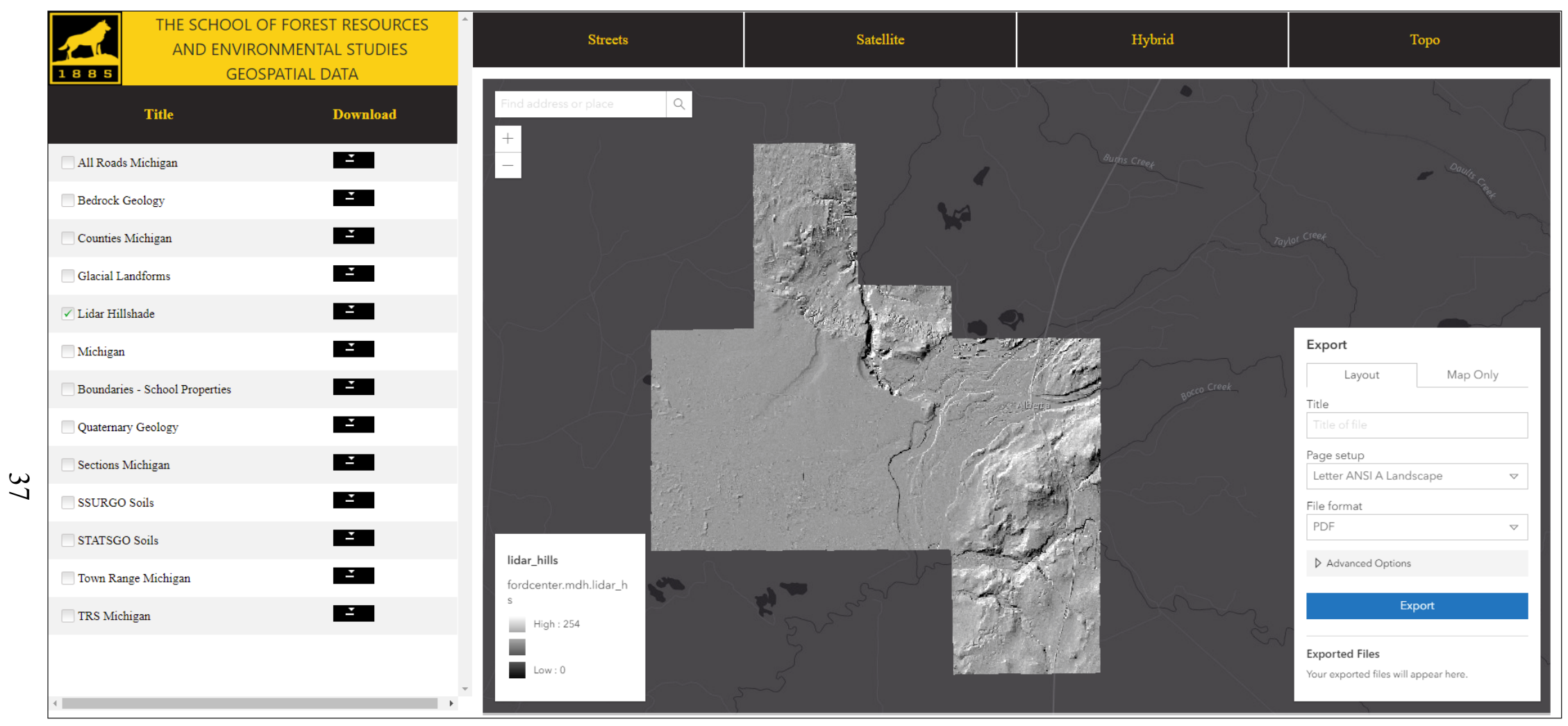

Figure 2.3. Adding a hillshade (Interface of the application created by author). 


\section{- Feature Layer}

The Feature Layer gets information from a server, which requires ArcGIS Server 10 or above (ESRI, Developers ArcGIS, Feature Layer 2017).

With feature layer tag, feature layer was added to the map (Figure 2.4).

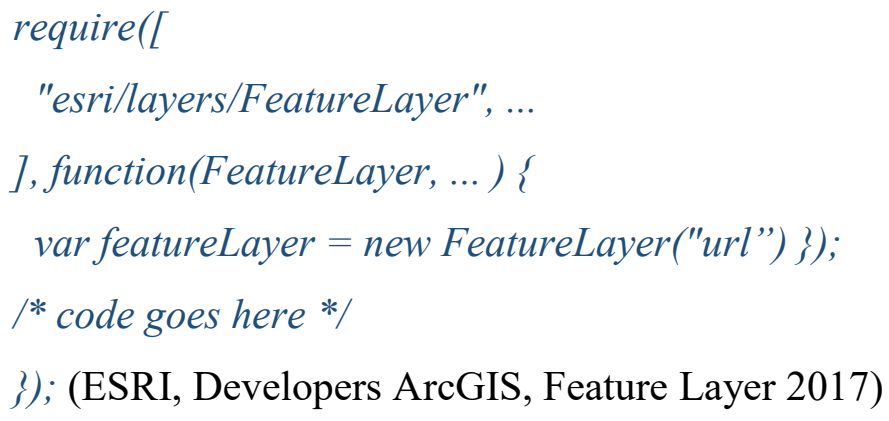




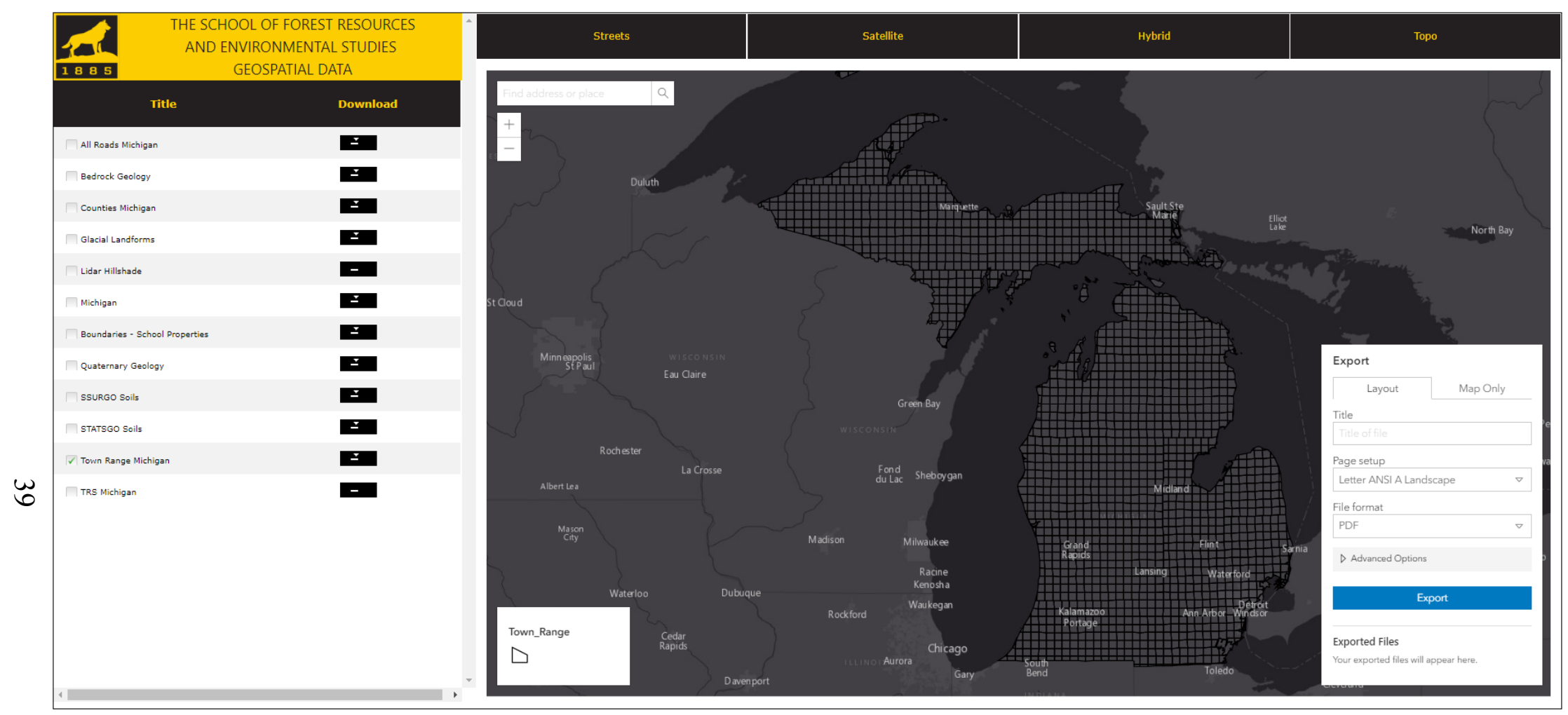

Figure 2.4. Adding Feature Layer (Interface of the application created by author). 
Views

- Map View

A MapView represents a 2D view of a location using center, scale and rotation. Summarize of the code displays on Table 2.2.

require([

"esri/view/MapView "],

function(MapView) \{

var mview = new MapView $(\{$

center: [-118.2438934, 34.058481],

container: "viewDiv",

map: map,

scale: 100000 \});

\}); (ESRI, Developers ArcGIS, Map View 2017)

Table 2.2. Property overview (ESRI, Developers ArcGIS, Map View 2017).

\begin{tabular}{|l|l|}
\hline \multicolumn{1}{|c|}{ Name } & \multicolumn{1}{c|}{ Description } \\
\hline center & The view's center point is represented. \\
\hline container & The ID or node that holds the view. \\
\hline map & An example of a Map object to presents in the view. \\
\hline scale & Stands for the map scale at the view center. \\
\hline padding & Making the center and extent. \\
\hline
\end{tabular}

The differences between different scales with the same center point are illustrated in Figure 2.5 and Figure 2.6. When scale number increases, percent of zooming increases. 


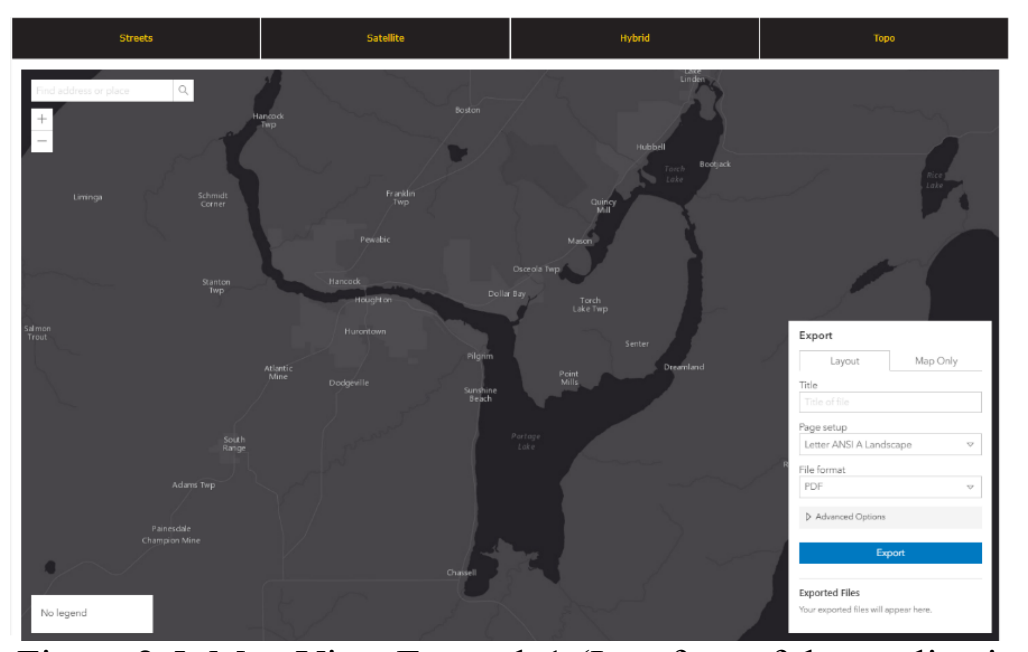

Set the scale: 100.000 and center: [-88.5, 47.1].

$\pm$

Figure 2.5. Map View Example1 (Interface of the application created by author).

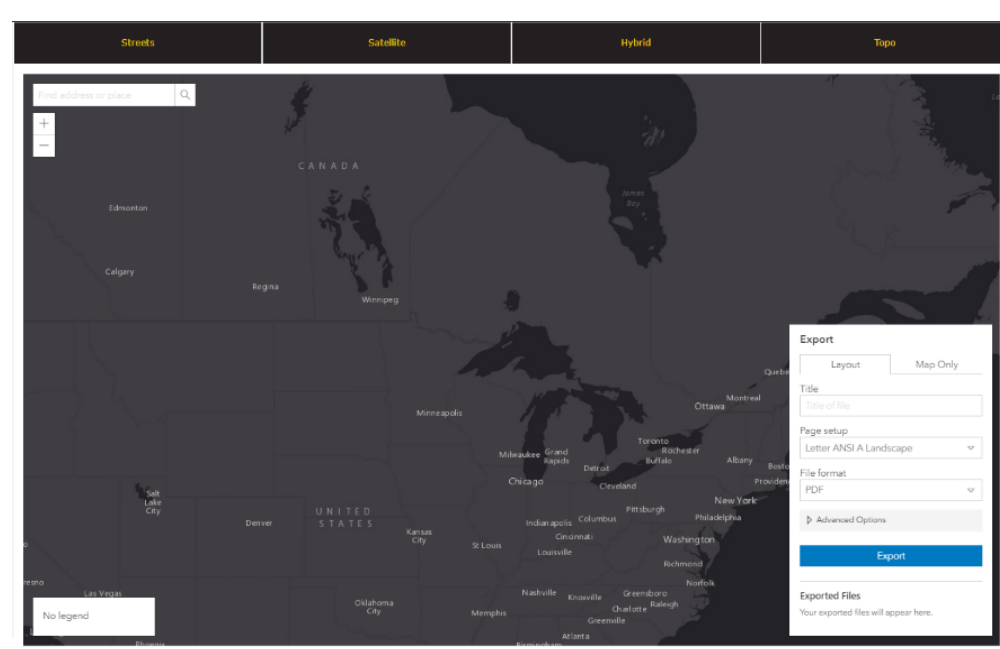

Set the scale: 10.000 .000 and center: $[-88.5,47.1]$.

Figure 2.6. Map View Example2(Interface of the application created by author). 


\section{Widget}

- Search

Operations can be query such as locator service(s), map/feature service feature layer(s) with using the Search widget (ESRI, Developers ArcGIS, Search Widget 2017). As is seen on Figure 2.7, there is a textbox and search is accessed through the textbox. Search widget displays appropriate data and it can be clicked on a search result item name, or used search options $Q$ button on the search window to focus on a place. It can also be deleted with close $\times$ button (on Figure 2.8). After searching any place with the search widget, as is seen in figure 2.9, it gives a point of the location, which is sought out with $\odot$ Zoom to button and it makes to zoom to the location more.

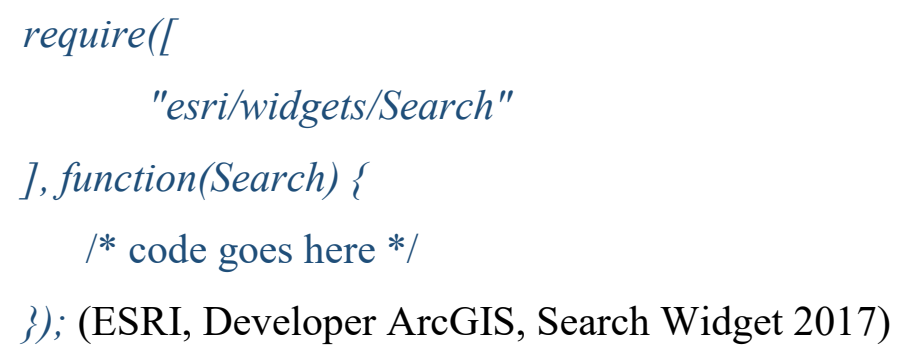




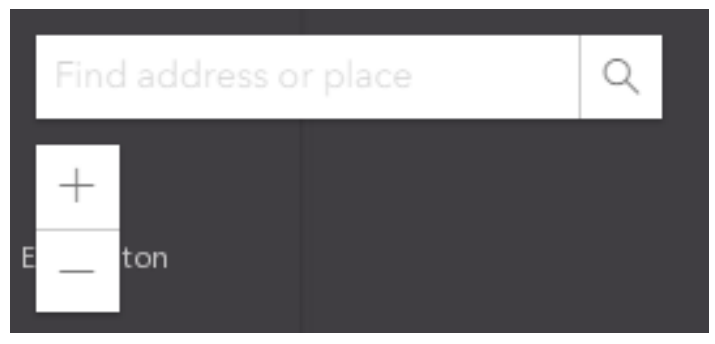

Figure 2.7. Search, zoom in and zoom out widget (Interface of the application created by author).

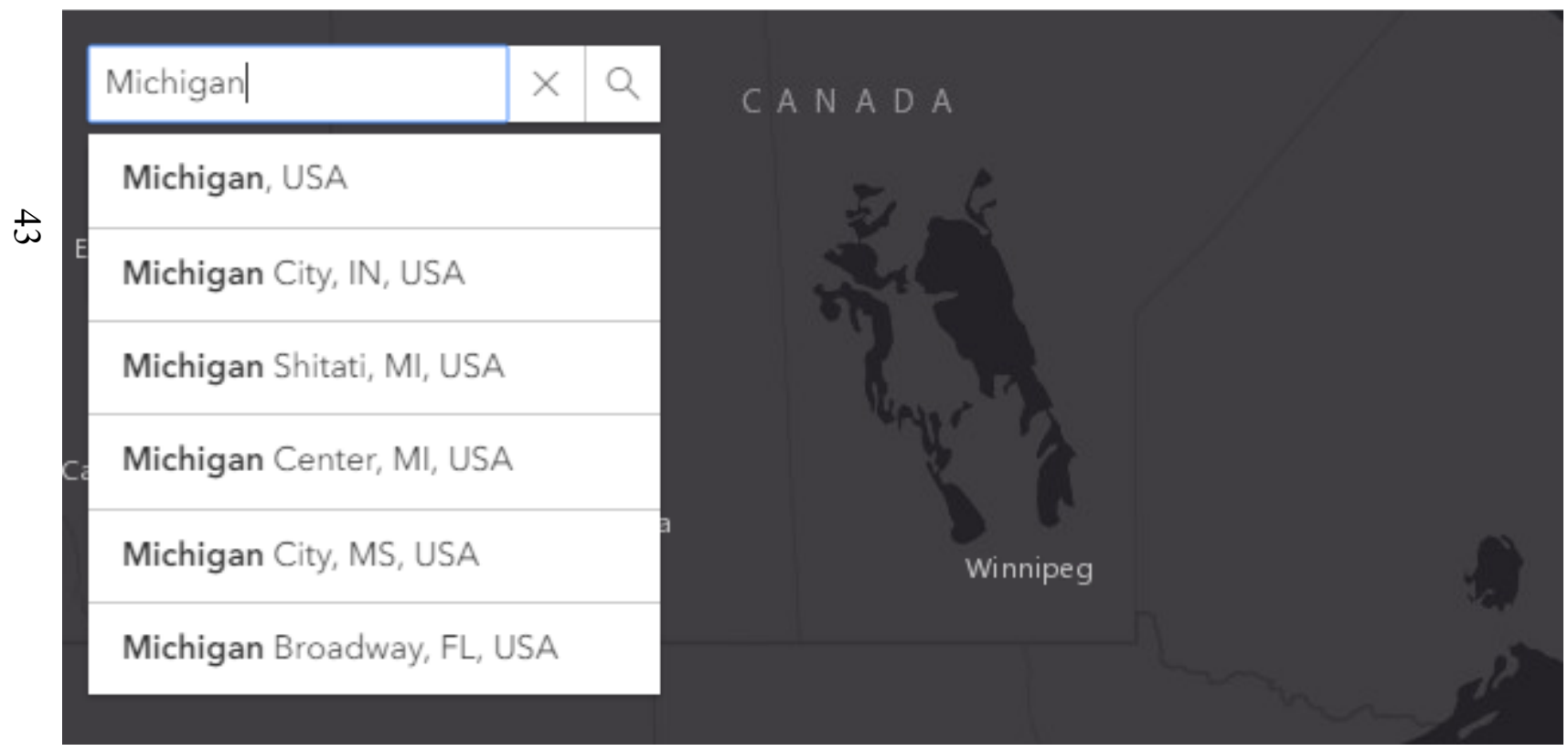

Figure 2.8. Search widget (Michigan, USA) (Interface of the application created by author). 


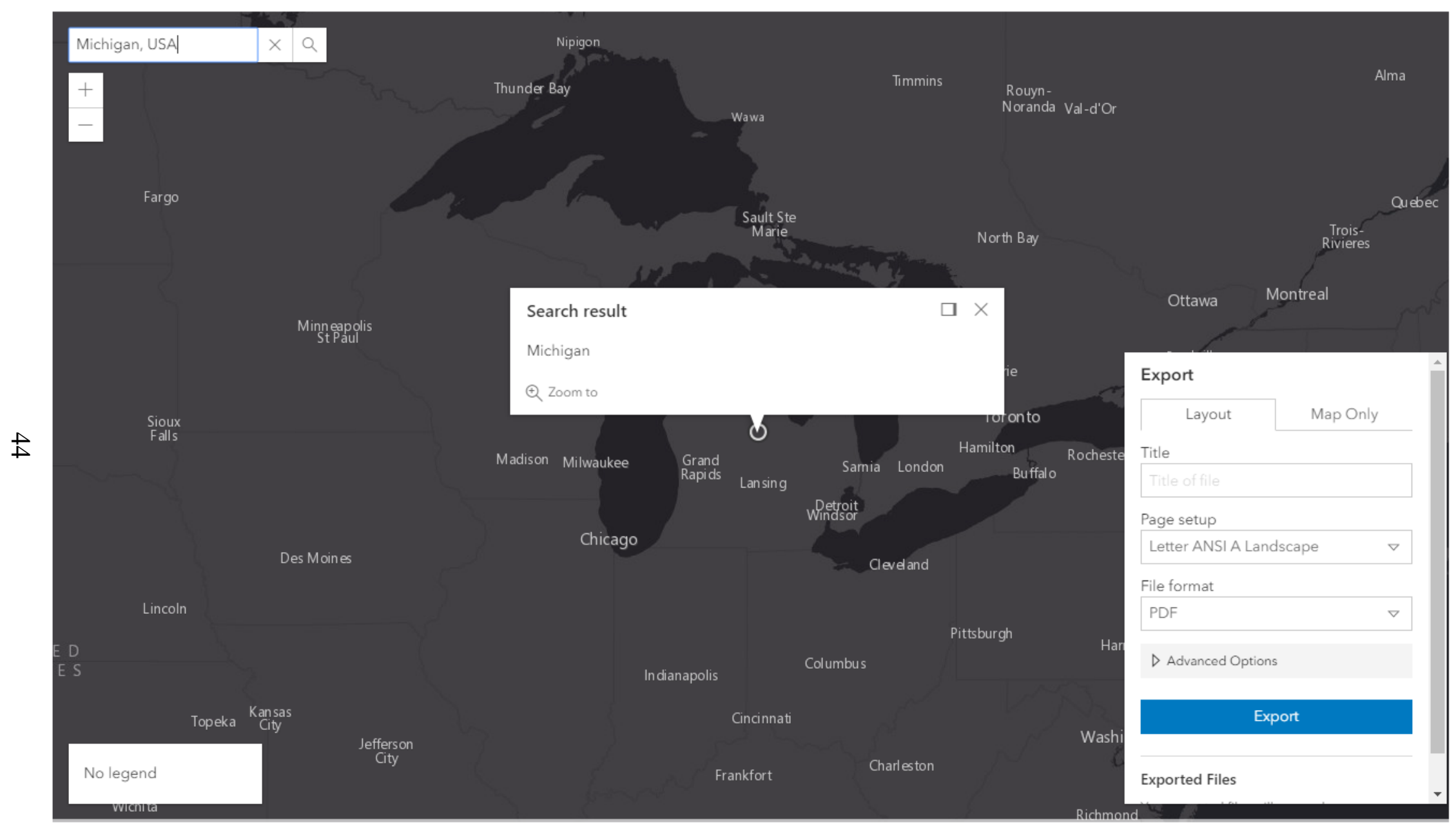

Figure 2.9. Search widget (Michigan, USA) (Interface of the application created by author). 
- Legend

Labels and symbols for layers can displayed in a map by the Legend (ESRI, Developers ArcGIS, Legend Widget 2017). In Figure 2.10, when any data is unchecked, no legend is shown on the screen. When zooming out from the map, layer is evaporated so no legend is shown on the screen again. As shown on Figure 2.11, one of the data added to the map and current zooming is enough to display the legend on the screen.

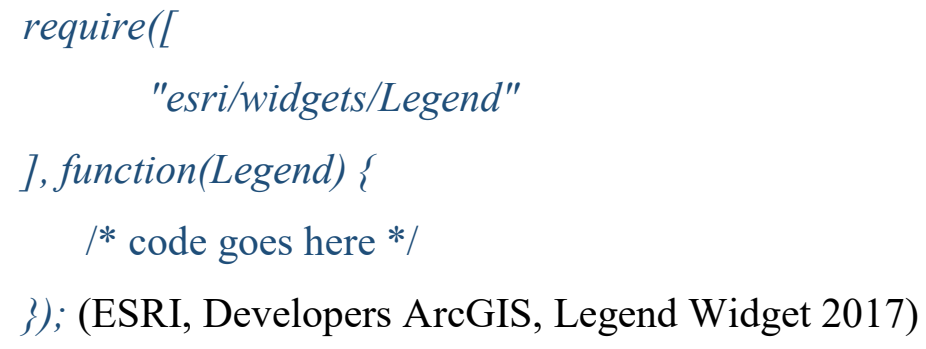




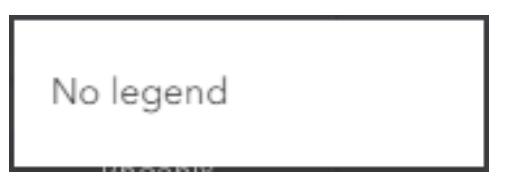

Figure 2.10. Legend (Interface of the application created by author).

bedrock_geo

label

ANTRIM SHALE

ARCHEAN GRANITE \& GNEISSIC

a

ARCHEAN ULTRAMAFIC

ARCHEAN VOLCANIC \& SEDIMENTARY

badwater greenstone

BASS ISLAND GROUP

BAYPORT LIMESTONE

Bedford shale

Bell shale

BEREA SANDSTONE \& BEDFORD

BIG HILL DOLOMITE

Figure 2.11. An example of legend (Interface of the application created by author). 


\subsubsection{Dojo}

The dojo toolkit is used because the application behaves the same in different browsers and it simplifies the development process. The application works with three different browsers, Google Chrome, Internet Explorer and Mozilla (Figure 2.12, Figure 2.13 and Figure 2.14) (ESRI, Developers ArcGIS, _dojo 2017). Here are some common functions used for the application.

$>$ On

This method for registering an event handler.

require([

$$
\text { "dojo/on"], }
$$

function( on ) \{

view.on("click", function(event)\{

map.add(Layer);

3); (ESRI, Developers ArcGIS, dojo 2017) 
囷 THE SCHOOL OF FORES $x$

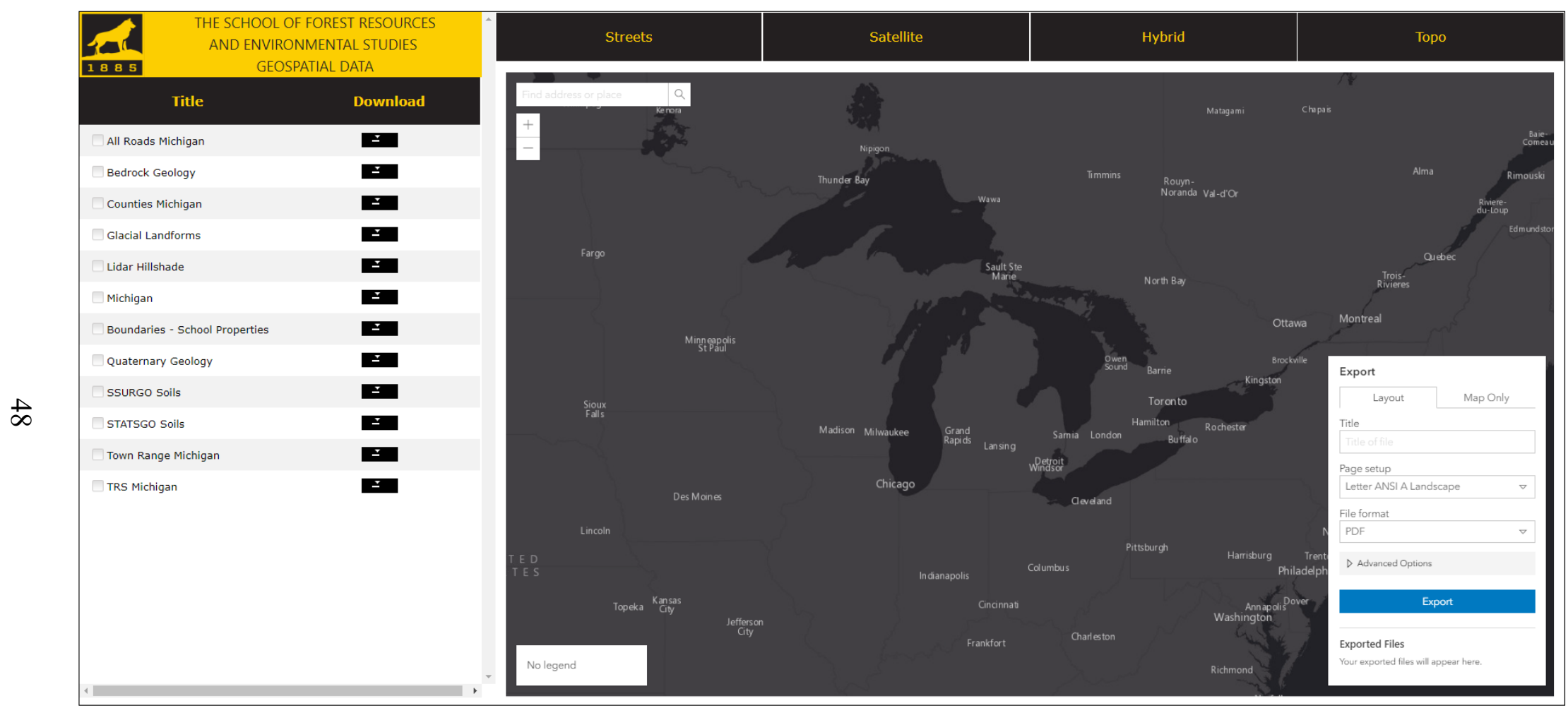

Figure 2.12. The application with Google Chrome (Interface of the application created by author). 


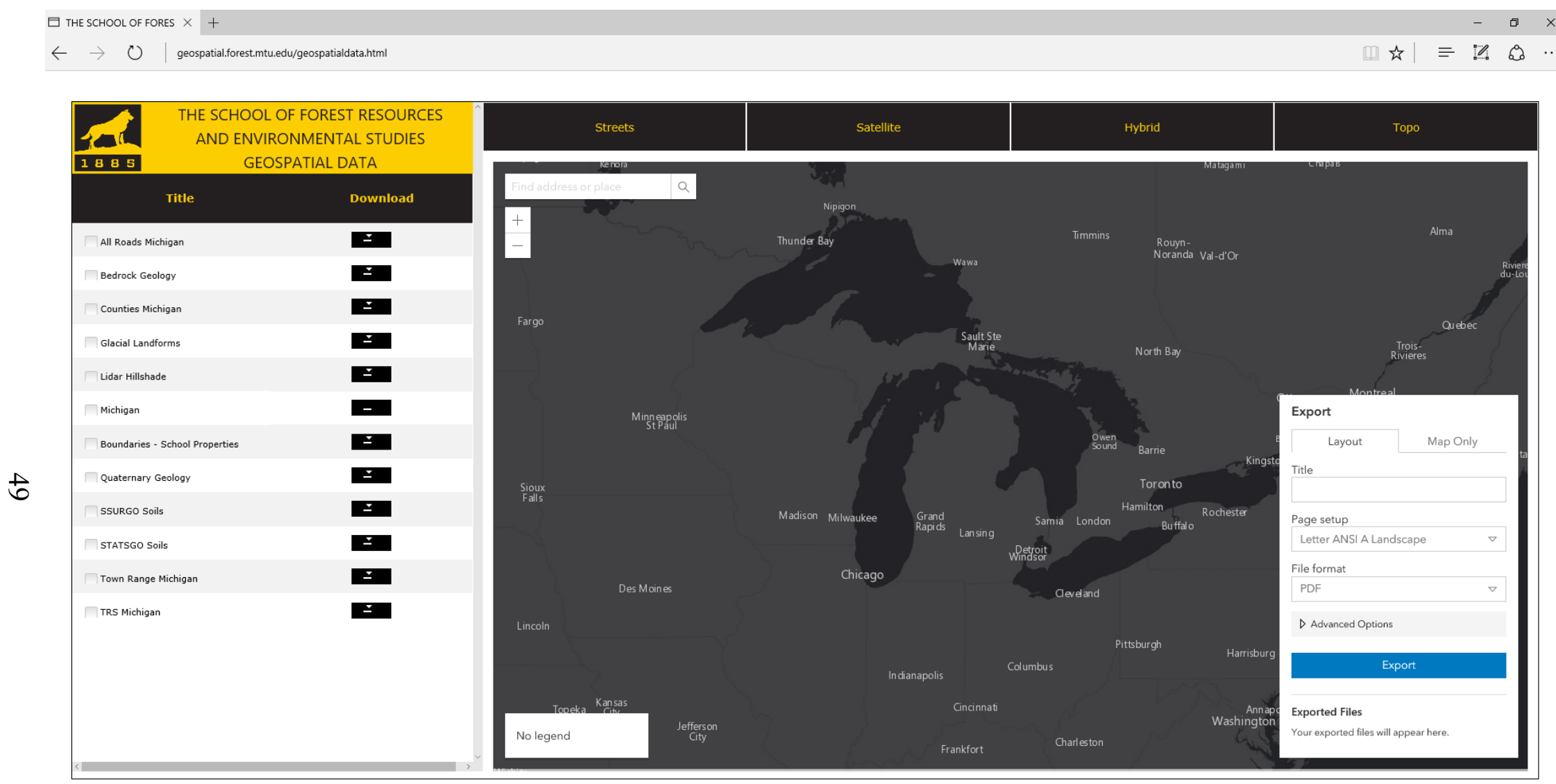

Figure 2.13. The application with Internet Explorer (Interface of the application created by author). 
THE SCHOOL OF FOREST ... $\times+$

4 (1) geospatial.forest.mtu.edu/geospatialdata. html

c Q Search

名自

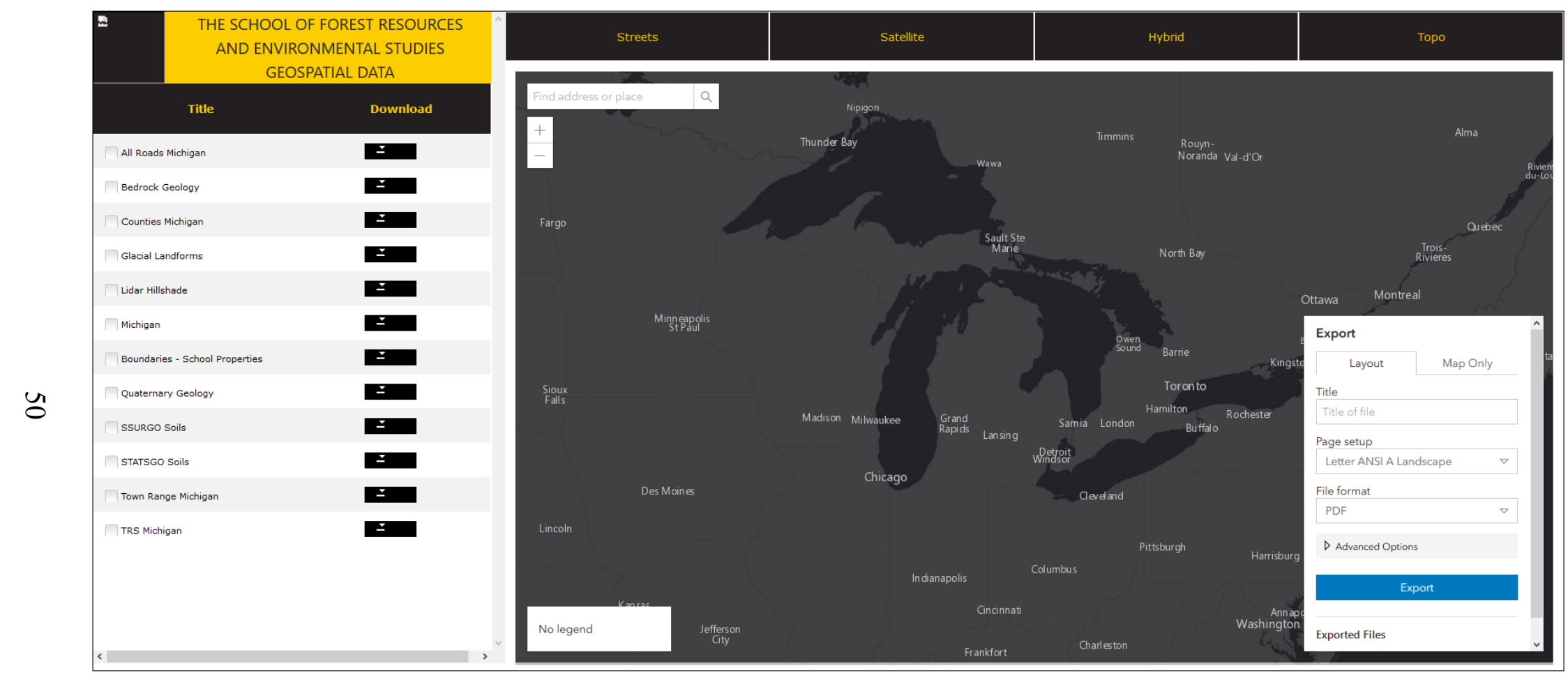

Figure 2.14. The application with Mozilla (Interface of the application created by author). 


\section{$>$ DOM}

DOM stands for Document Object Model and it describes the core Dojo DOM API.

$$
\begin{aligned}
& \text { require([ } \\
& \text { "dojo/dom"] } \\
& \text { function(dom) }\{ \\
& \text { /* code goes here */ } \\
& \text { \}); (DojoToolkit 2017) }
\end{aligned}
$$

\section{$>$ DOMReady}

DOMReady defers the function by DOM is ready (DojoToolkit 2017).

$$
\begin{aligned}
& \text { require([ } \\
& \text { "dojo/DomReady"], } \\
& \text { function( ) } \\
& \text { /* code goes here */ } \\
& \text { \}); (DojoToolkit 2017) }
\end{aligned}
$$




\section{Chapter - Results and Discussion}

\subsection{Introduction}

A diagram of the website sequence in a complex system is displayed in Figure 2.1. Data is presented as an ArcGIS REST service such as Map Server, and Feature Server services to make the data accessible to a web map. Then a website is created by using ArcGIS JavaScript API. This website enables downloading data that are feature classes, and/or raster data, such as slope and aspect. Furthermore, maps in 2D can be displayed and datadriven visualization created. The feature classes displayed on maps and legends are displayed via the legend widget. The scale bar is also shown in the window. The app is programmed to create cartographically correct maps which include a neat line, border, title, scale, legend, credits, place-name, inset, ground and figure.

\subsection{Web Application}

The overall website displays (Figure 3.1) is separated into two components. The right side contains the map display, and the left side lists the available spatial data for creating the map. 


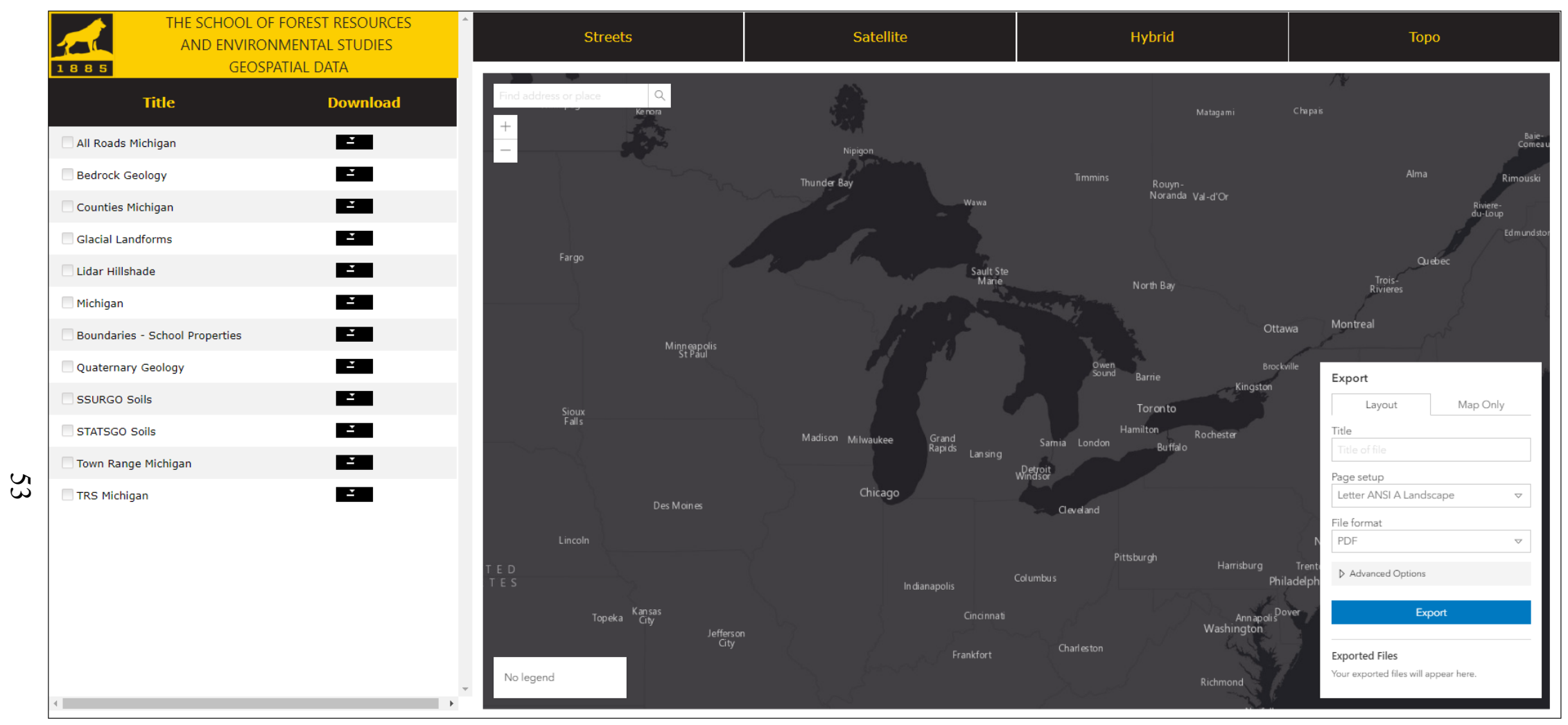

Figure 3.1. Website overall display (Interface of the application created by author). 


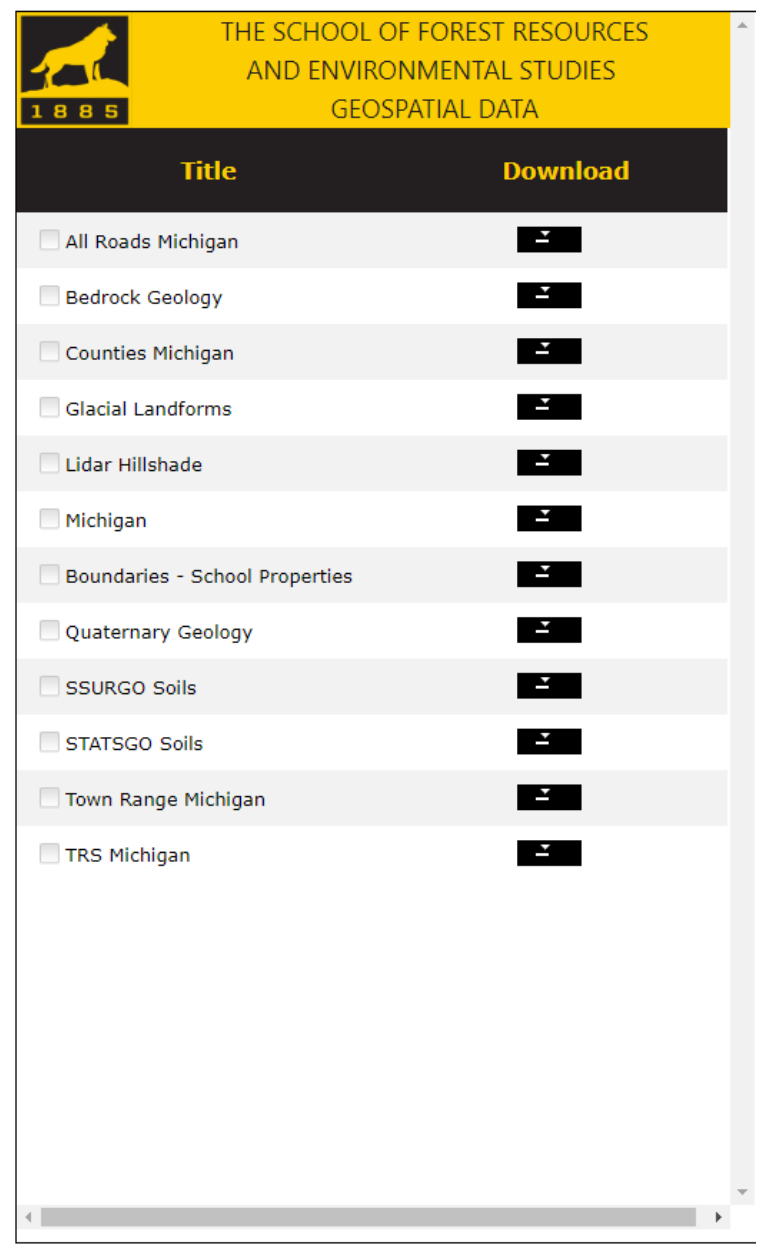

Figure 3.2. SFRES geospatial data tree (Interface of the application created by author).

On the left side of the application, (Figure 3.2), all publically accessible data from the online ArcGIS Server is displayed. When a checkbox is selected, the data displays in the map viewer on the right side of the display. When the download button is clicked (Figure 3.3) the selected data downloads from the server (Figure 3.4). 


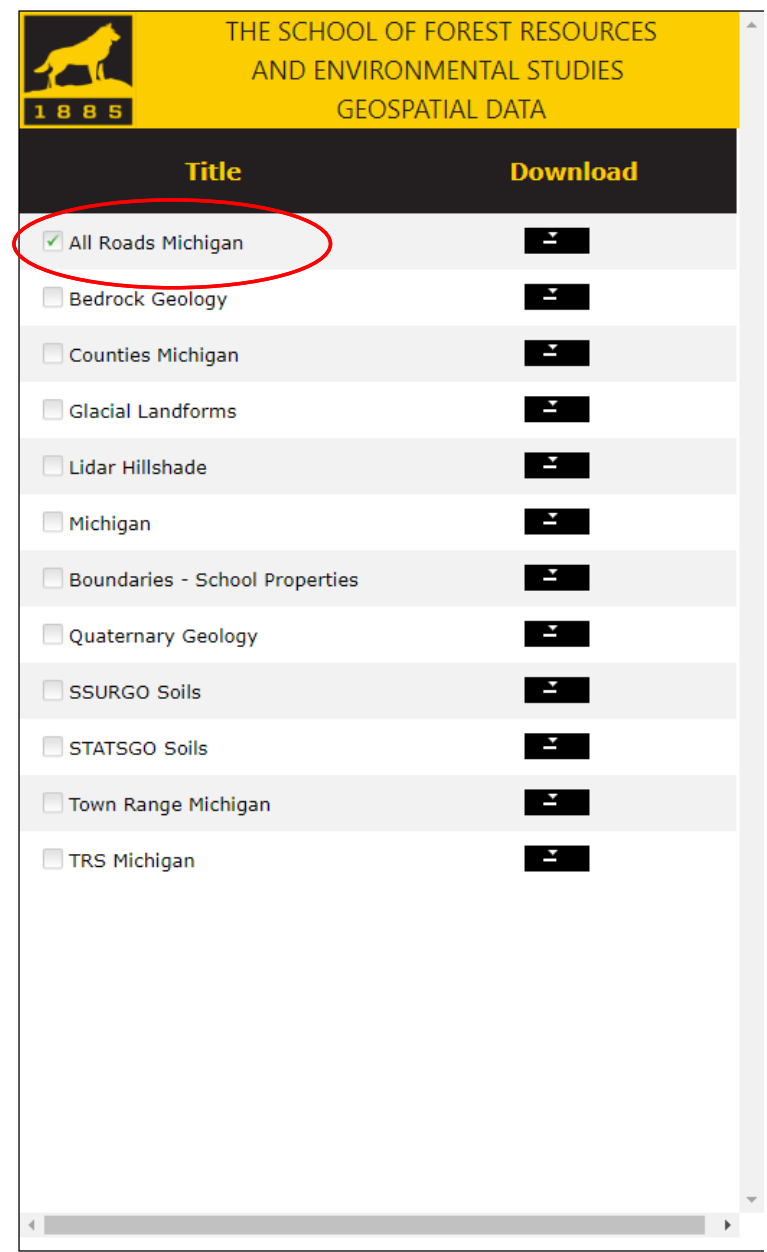

Figure 3.3. SFRES geospatial data tree (checked one) (Interface of the application created by author). 


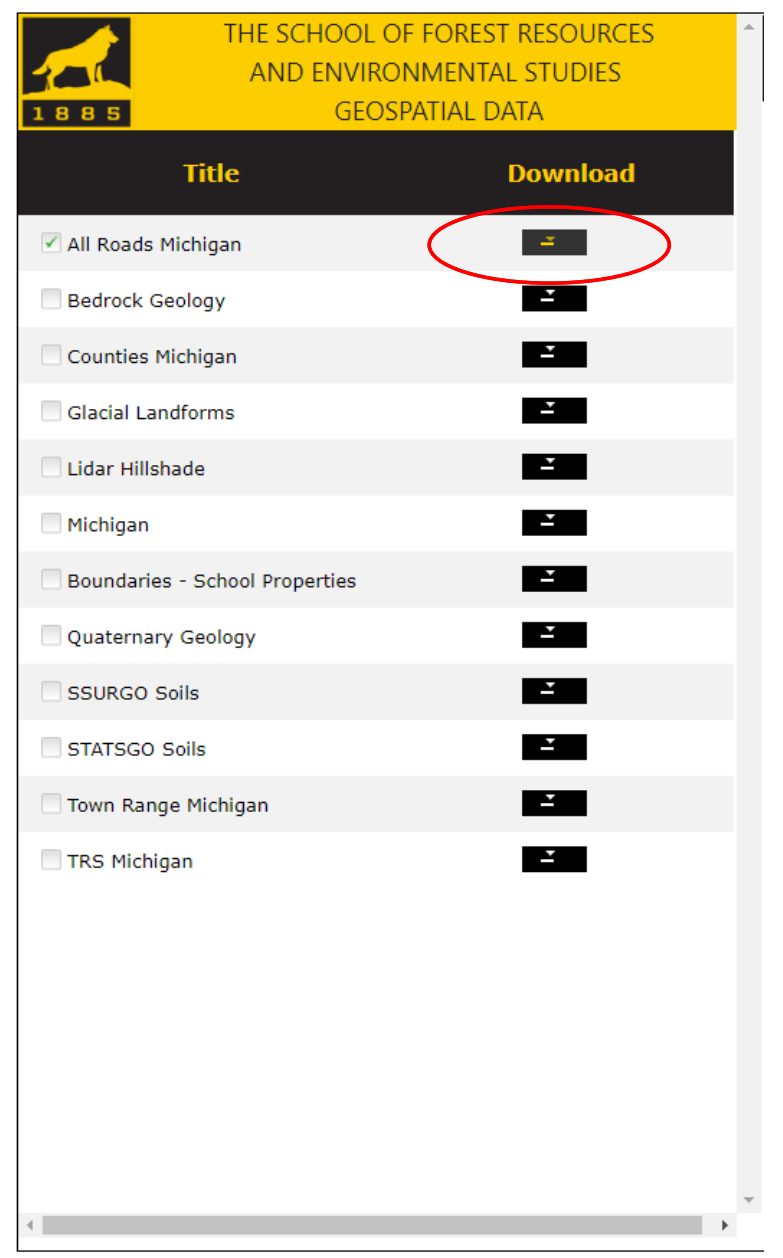

Figure 3.4. SFRES geospatial data tree (downloaded one) (Interface of the application created by author).

The map viewer is capable of displaying four basic map types- Street (Figure 3.5), Satellite (Figure 3.6), Hybrid (Figure 3.7), or Topo (Figure 3.8). The type of base-map is easily changed by clicking on any of the four buttons. 


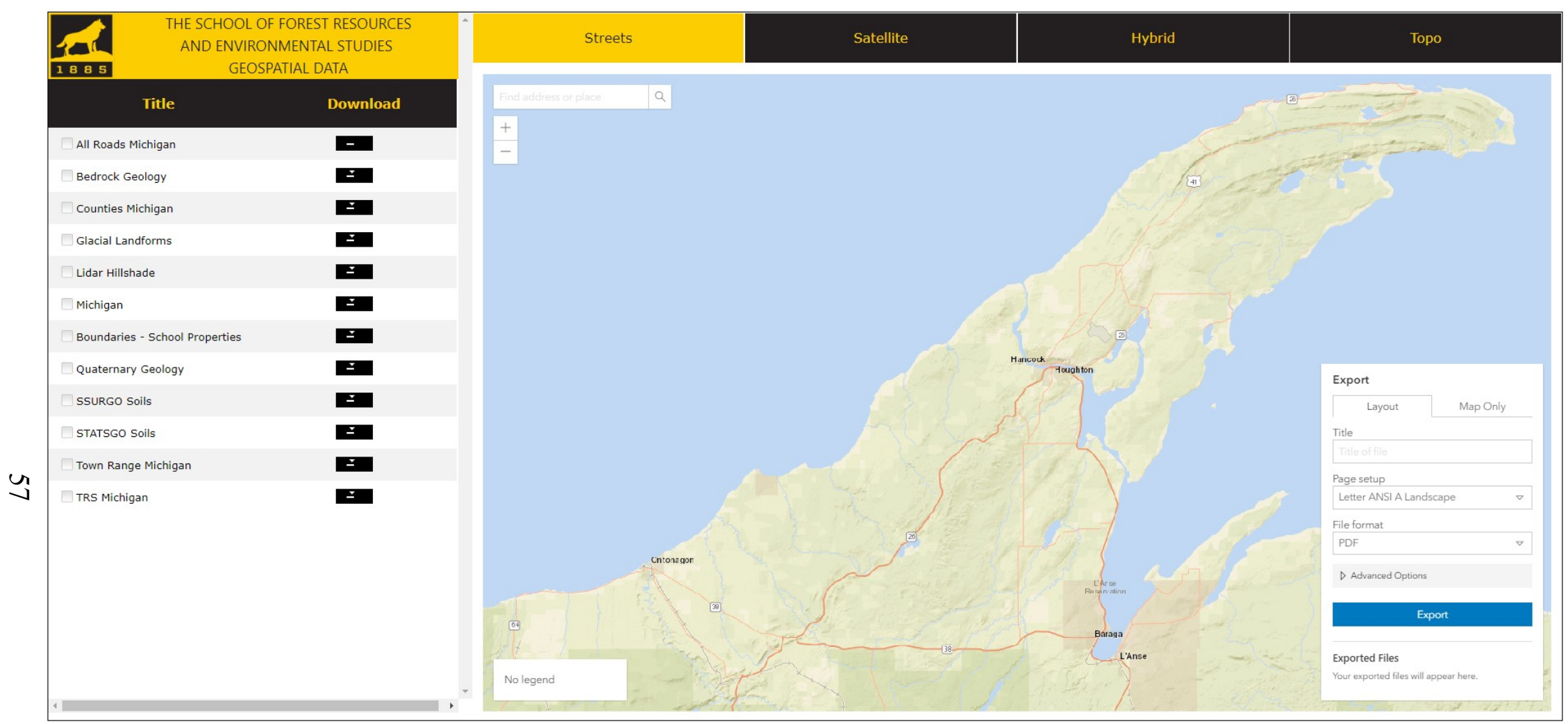

Figure 3.5. Website overall display with street map (Interface of the application created by author). 


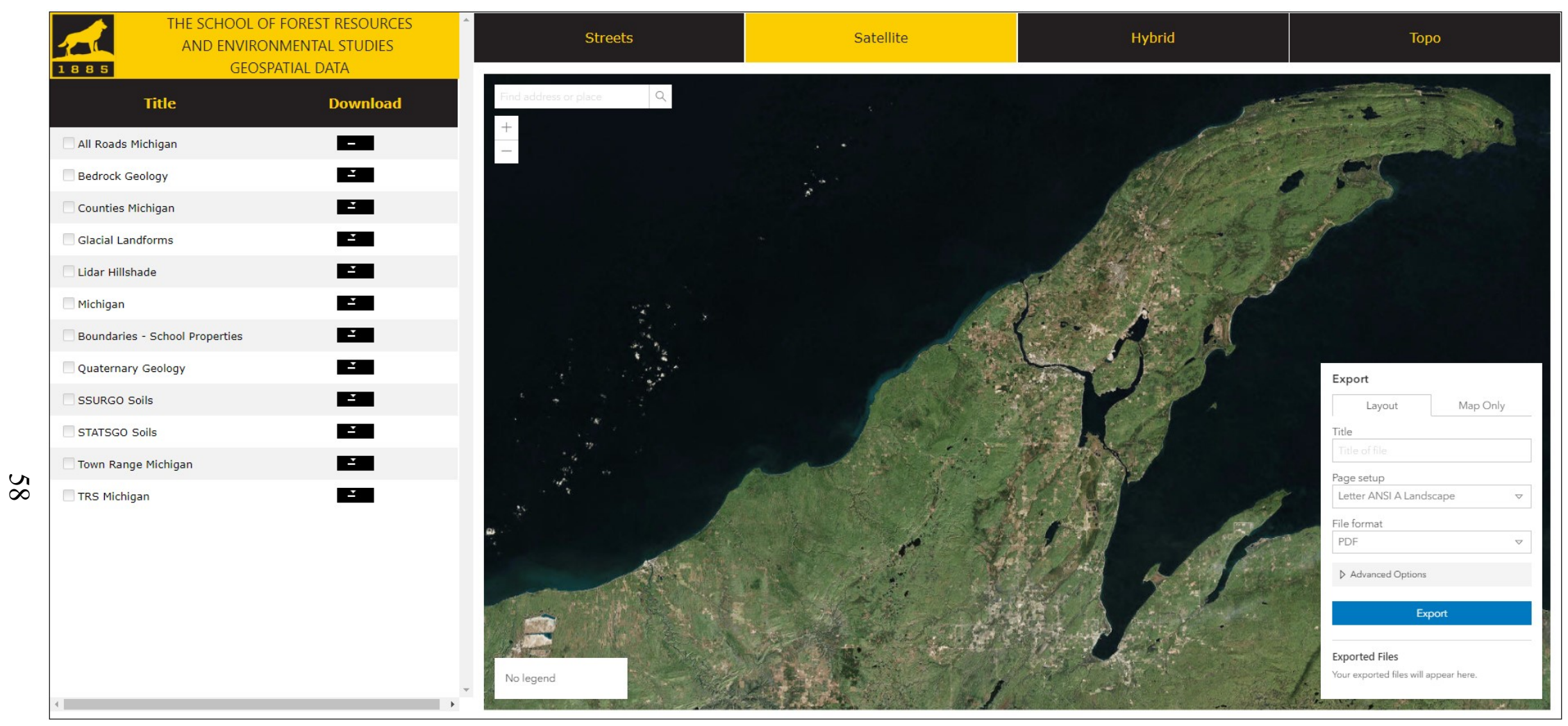

Figure 3.6. Website overall display with satellite map (Interface of the application created by author). 


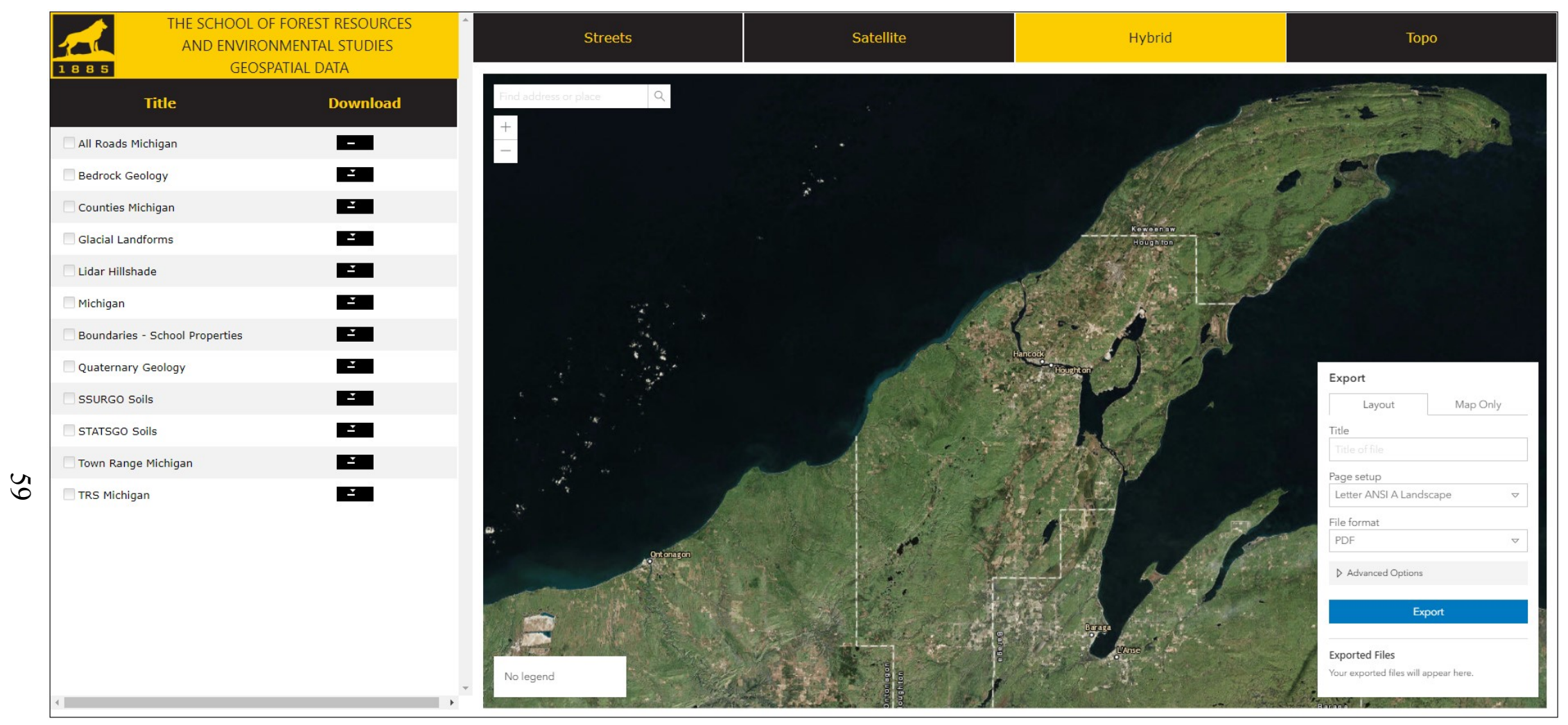

Figure 3.7. Website overall display with hybrid map (Interface of the application created by author). 


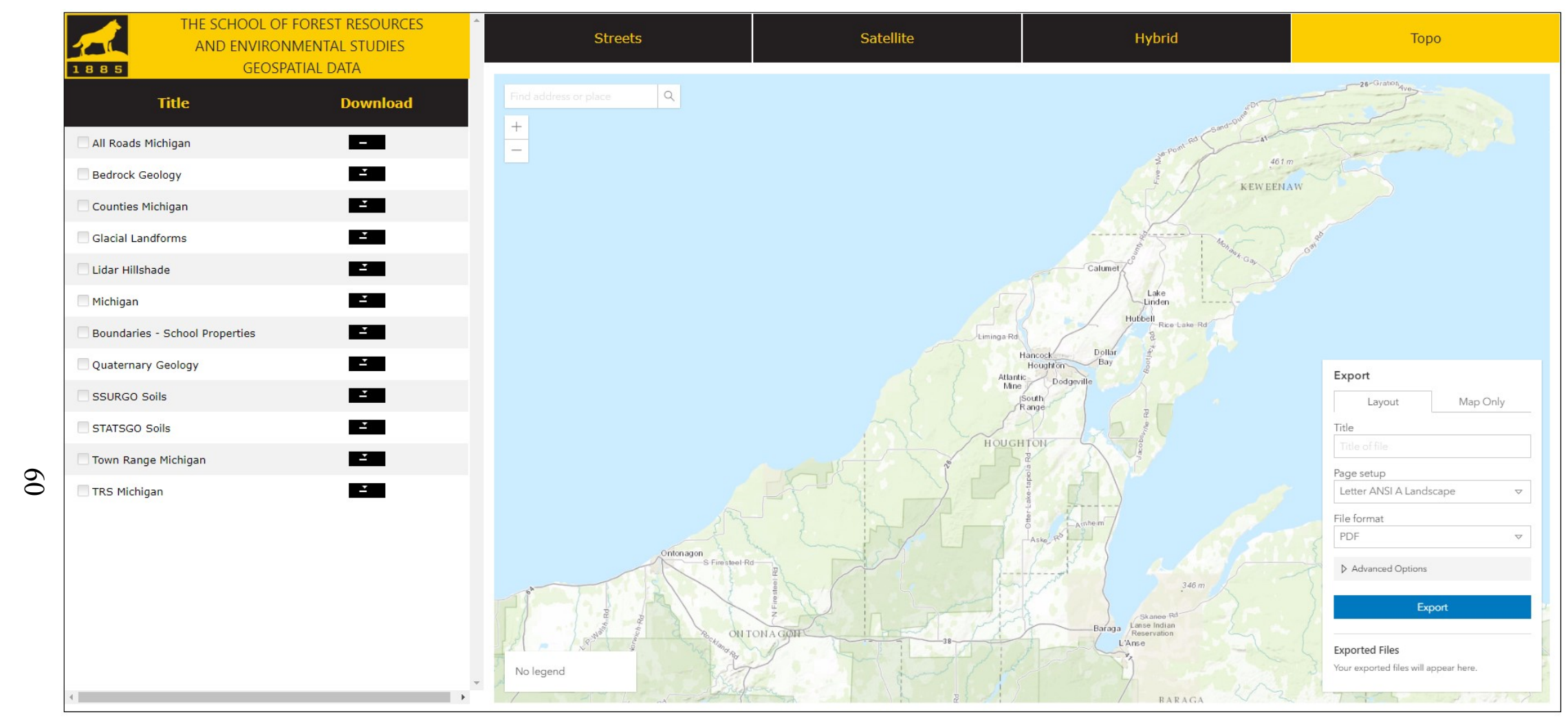

Figure 3.8. Website overall display with topo map (Interface of the application created by author). 
On Figure 3.9, focusing on the button of the basics maps, it is observed that button color is black and the font color is yellow. When one of the button of the basic maps is selected its' color is changing and it can be realized which one is selected (see Figure 3.10).

\section{Streets}

Satellite

Hybrid

Topo

Figure 3.9. Basic map types (Interface of the application created by author).

Figure 3.10. Basic map types (chosen streets) (Interface of the application created by author).

There is a search button on left-top side (Figure 3.11), which runs locator service(s) and map/feature service feature layer(s). After selecting or typing a location, the area of interest is displayed.

Below the search button, are the zoom in and zoom out options.

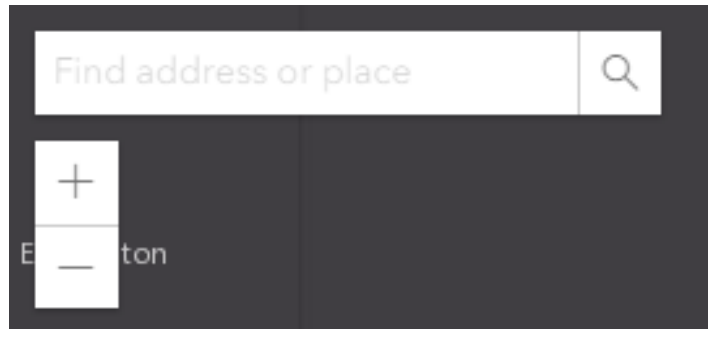

Figure 3.11. Search widget (top), and zoom in and zoom out button (Interface of the application created by author).

The legend widget is found at the left bottom side of the map viewer and it displays the legend information after the selected thematic layers, and downloaded and displayed on the map. The legend may be scrolled up and down if needed to see the information associated with the selected thematic layers. 
One of the aims for this project was easily getting a cartographically correct map. As shown on the Figures 3.12, 3.13 and 3.14, the map layout is completed by filling in the desired information. If needed, the map can be easily printed. 


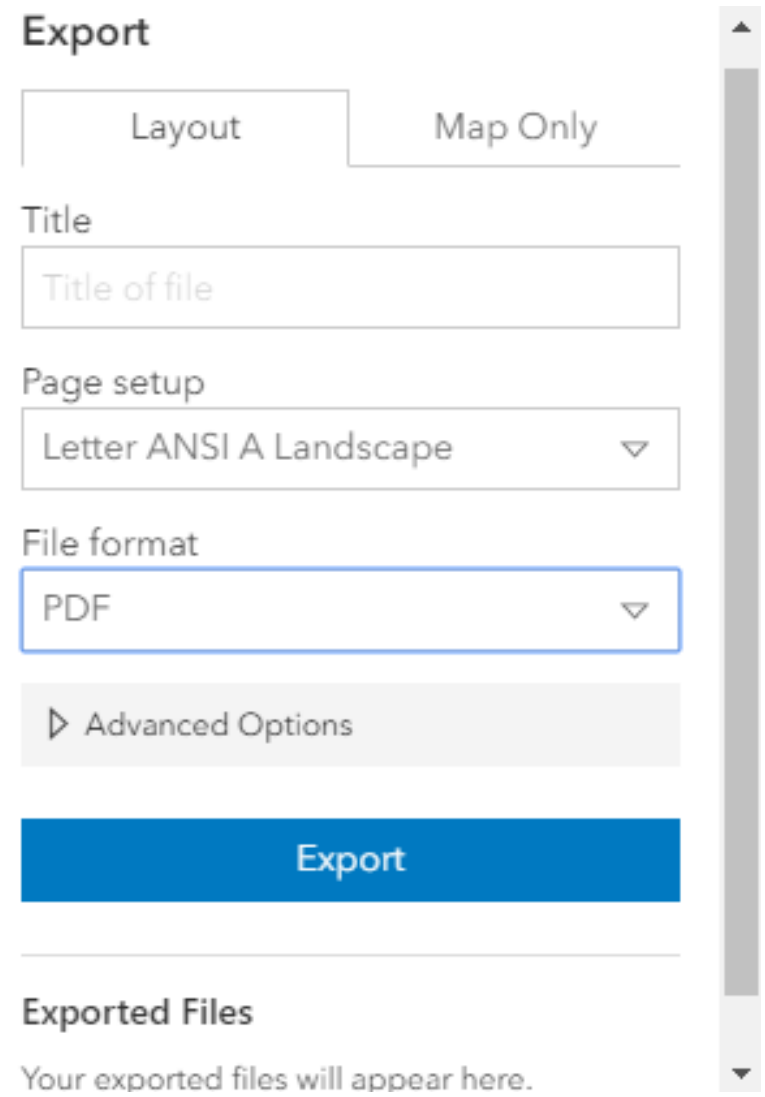

Figure 3.12. Export - Layout (Interface of the application created by author).

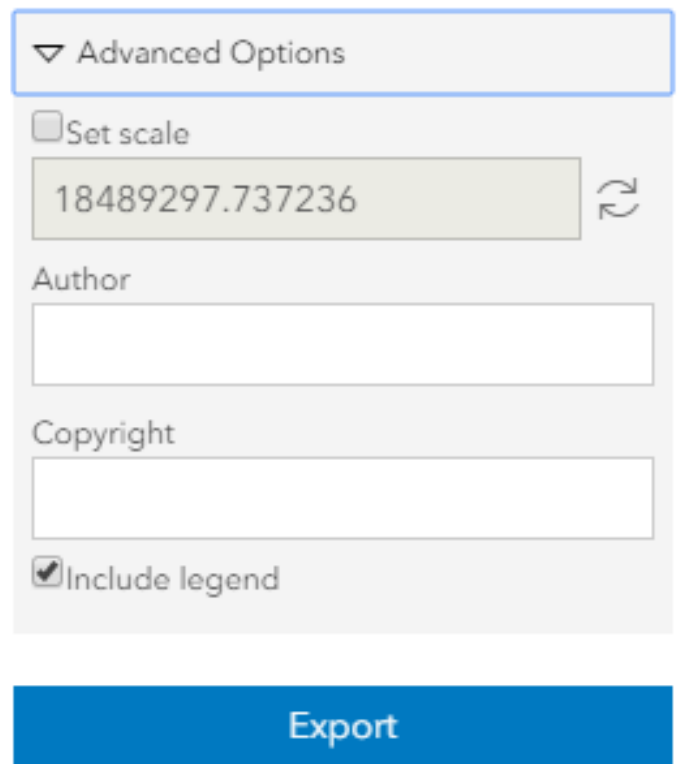

Figure 3.13. Export - Layout - Advanced Options (Interface of the application created by author). 


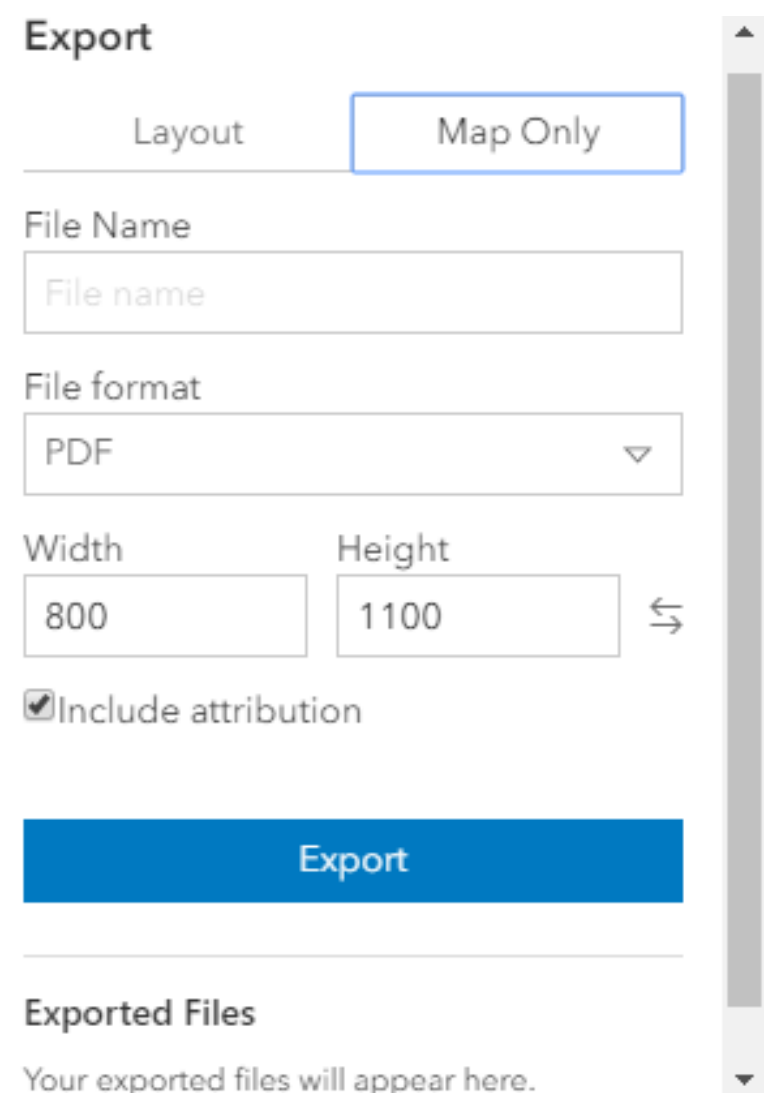

Figure 3.14. Export - Map Only (Interface of the application created by author).

On the Export Layout page, a title textbox is available to create the map title. Page size uses the 8 different paper sizes recognized by ESRI.

- Letter ANSI A Landscape

- A3 Landscape

- A3 Portrait

- A4 Landscape

- A4 Portrait

- Letter ANSI A Portrait

- Tabloid ANSI B Landscape

- Tabloid ANSI B Portrait

There are also eight type of export file formats to select from. 
- PDF

- PNG32

- PNG8

- JPG

- GIF

- EPS

- SVG

- SVGZ.

In the Advanced Options (Figure 3.13) an option is available to set the scale. There are also Author and Copyright text boxes, which are displayed in the bottom-right of the map view. If the legend checkbox is selected, the legend is included in the exported map.

Clicking the Export button will generate a file with the chosen file format (Figure 3.15). 


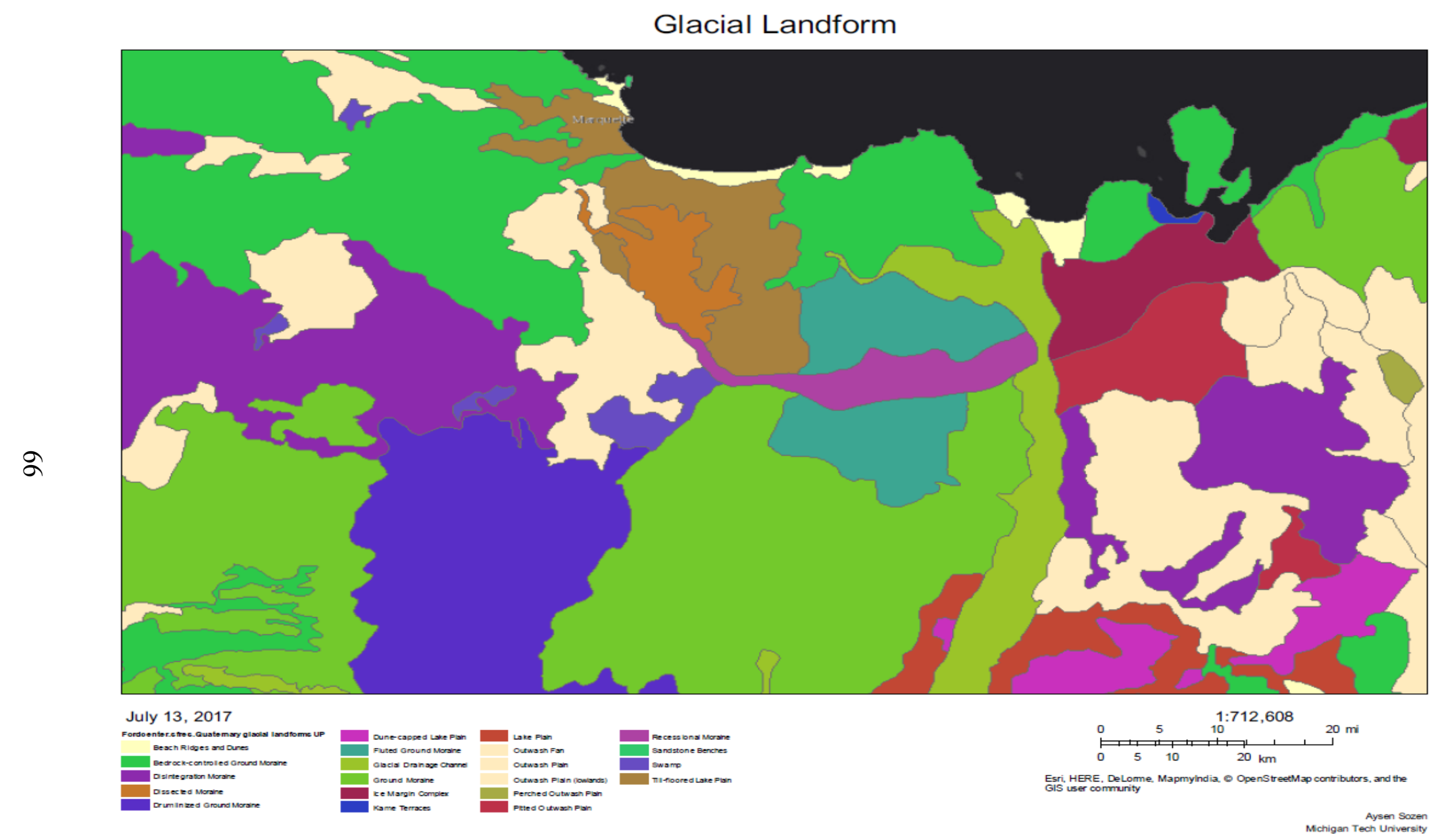

Figure 3.15. Example of a cartographic correct map layout ready to be exported and printed if desired (Displaying an exported map from the application created by author). 
For simplicity and quick viewing there is a Map Only option (refer back to Figure 3.14). The file name can be written and there are same file formats used for the annotated map are available. The width and height of map may also be set. After giving a name to the file, choosing file format as a pdf document, setting width and height as default values and checking include attribution check box, the map is exported by clicking the export button (Figure 3.16). 


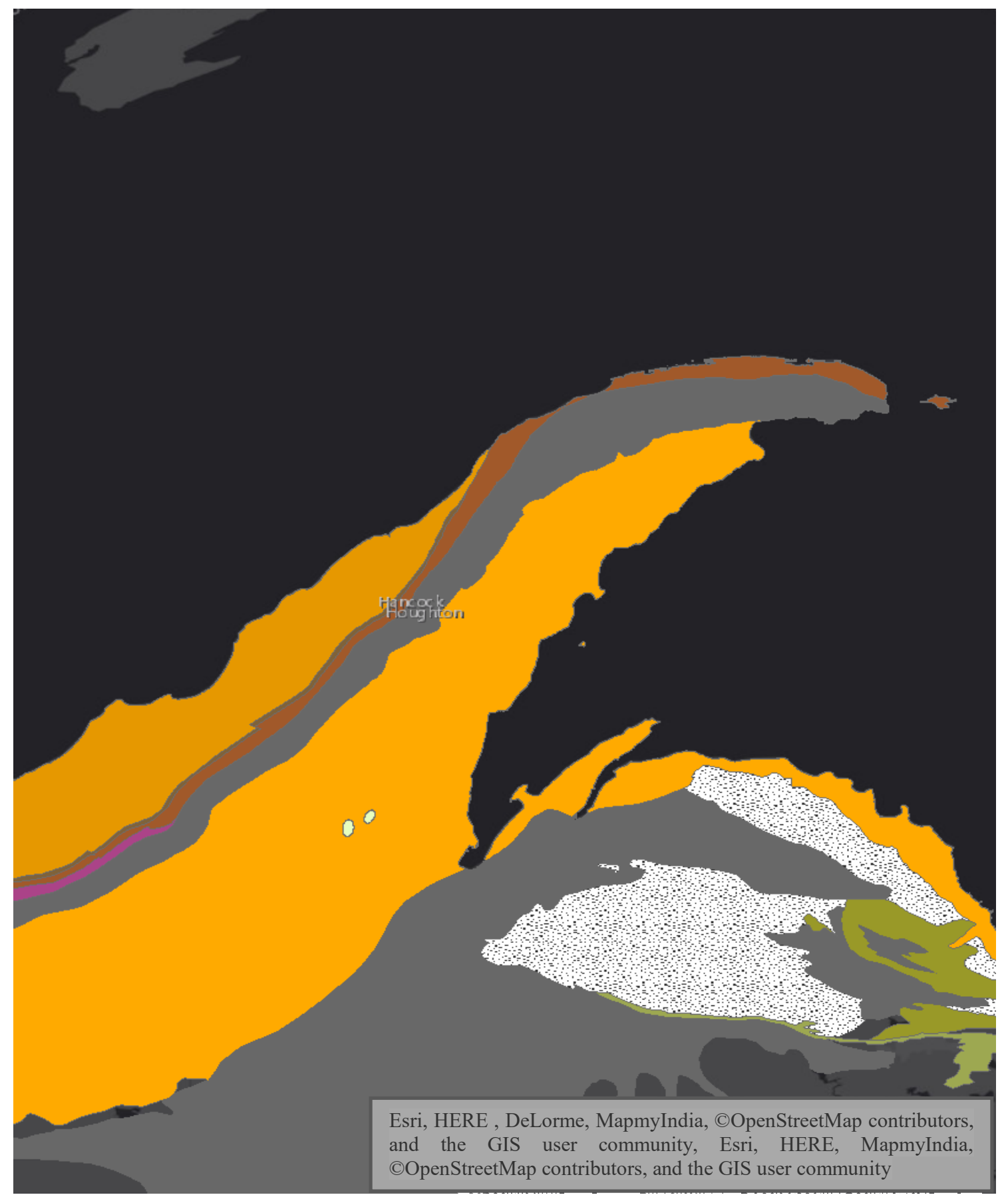

Figure 3.16. An example of map only display (Displaying an exported map from the application created by author). 


\section{Copyright Permission}

\section{Figure 1.1. Architecture of a Single ArcGIS Server Machine \& Figure 1.2. Architecture of Multiple ArcGIS Servers in Multiple-Machine}

Esri grants the recipient of the Esri information contained within the esri.com Web site the right to freely reproduce, redistribute, rebroadcast, and/or retransmit this information for personal, noncommercial purposes, including teaching, classroom use, scholarship, and/or research, subject to the fair use rights enumerated in sections 107 and 108 of the Copyright Act (Title 17 of the United States Code). All copies, whether in whole or in part, shall include the appropriate Esri copyright notice.

http://www.esri.com/legal/copyright-trademarks

\section{Figure 2.1. Producing maps with ArcGIS API for JavaScript}

I am completing a master thesis at Michigan Technical University entitled "Online

Mapping Application Development for the School of Forest Resource and

Environmental Science Geospatial Data." I would like your permission to reprint in my

thesis excerpts from the following:

The excerpts to be reproduced is the Figure 2.1.

The requested permission extends to any future revisions and editions of my thesis, including non- exclusive world rights in all languages. Michigan Technological University will make my thesis available for free internet download at my request. These rights will in no way restrict republication of the material in any other form by you or by others authorized by you. Your signing of this letter will also confirm that you own the copyright to the above- described material.

Permission granted for the use requested above by the author, Rene Rubalcava on 4 of the October in 2017. 


\section{References}

Alesheikh, A Ali, H Helali, and H A Behroz. 2002. "Web GIS: Technologies and Its Applications." Symposium on Geospatial Theory, Processing and Applications, Symposium sur la théorie, les traitements et les applications des données Géospatiales. Ottowa, Canada. 1. Accessed July 14, 2017. http://www.isprs.org/proceedings/XXXIV/part4/pdfpapers/422.pdf.

Alibrandi, Marsha. 2003. GIS in the Classroom: Using Geographic Information Systems in Social Studies and Environmental Science. Portsmouth, New Hampshire: Pearson Education Canada, 2003.

Aly, Ahmed Gamal, and Nevine Makram Labib. 2013. "Proposed Model of GIS-based Cloud Computing Architecture for Emergency System." INTERNATIONAL JOURNAL OF COMPUTER SCIENCE AND MOBILE APPLICATIONS 17-28.

APIs, ESRI ArcGIS Web. 2017. ArcGIS for Developers, ArcGIS Web APIs. Accessed 08 16, 2017. https://developers.arcgis.com/web-api/.

Arctur, David, and Micheal Zeiler. 2004. Designing Geodatabases, Case Studies in GIS Data Modeling. Redlands, CA: ESRI.

Basu, Tanima, and P. K. Paul. 2016. "Creation of a web portal for dissemination of accident information of underground coal mines of Eastern Coalfields Limited, India, using web GIS." Int. J. Mining and Mineral Engineering 11.

Chang, Kang-tsung. 2014. Introduction to Geographic Information Systems. New York: Mc Graw Hill Connect Learn Succeed.

Davis, Scott. 2007. GIS for Web Developers, Adding Where to Your Web Applications. Edited by The Progmatic Programmers LLC. Raleigh, North Carolina Dallas, Texas: The Progmatic Bookshelf. Accessed July 14, 2017. http://www.r5.org/files/books/computers/languages/ruby/ext/Scott_DavisGIS_for_Web_Developers-EN.pdf.

DojoToolkit. 2017. Dojo, domReady, PlugIns. Accessed June 16, 2017. $<$ https://dojotoolkit.org/reference-guide/1.10/loader/amd.html $>$.

ESRI. 2017. ArcGIS Developers- ArcGIS API for JavaScript - ESRI - Map. Accessed 08 28, 2017. https://developers.arcgis.com/javascript/latest/api-reference/esriMap.html.

—. 2017. ArcGIS Enterprise, Installation Guides, Multiple-machine deployment with ArcGIS Web Adaptor. Accessed 08 21, 2017. http://server.arcgis.com/en/server/latest/install/windows/multiple-machinedeployment-with-arcgis-web-adaptor.htm. 
-. 2017. ArcGIS Enterprise, Installation Guides, Ports used by ArcGIS Server. Accessed 08 21, 2017.

http://server.arcgis.com/en/server/latest/install/windows/ports-used-by-arcgisserver.htm.

—. 2017. ArcGIS Enterprise, Installation Guides, Single-machine deployment. Accessed 08 21, 2017.

http://server.arcgis.com/en/server/latest/install/windows/single-machinedeployment.htm.

-. 2017. ArcGIS for Developers - ArcGIS API for JavaScript - Api Reference-Layer. Accessed 08 22, 2017. https://developers.arcgis.com/javascript/3/jsapi/layeramd.html.

Esri. 2017. ArcGIS for Developers, ArcGIS Server services overview. Accessed 0808 , 2017. https://developers.arcgis.com/javascript/3/jshelp/ags_overview.html.

—. 2017. ArcGIS Resources, The ArcGIS REST API. 07 27. Accessed 08 08, 2017. http://resources.arcgis.com/en/help/arcgis-rest-api/.

ESRI. 2017. ArcGIS Server, The ArcGIS Server Account. Accessed 08 26, 2017. $<$ http://server.arcgis.com/en/server/latest/administer/windows/the-arcgis-serveraccount.htm>.

—. n.d. ArcGIS-Resources-Dynamic Layer/Table. Accessed 09 22, 2017. https://resources.arcgis.com/en/help/rest/apiref/dynamicLayer.html.

-. 2017. Developer ArcGIS, Search Widget. Accessed June 12, 2017. $<$ https://developers.arcgis.com/javascript/latest/api-reference/esri-widgetsSearch.html $>$.

—. 2017. Developers ArcGIS. Accessed May 29, 2017. $<\mathrm{https}: / /$ developers.arcgis.com/javascript/3/>.

—.2017. Developers ArcGIS,_dojo. Accessed July 10, 2017. $<$ https://developers.arcgis.com/javascript/3/jshelp/inside_dojo.html $>$.

—. 2017. Developers ArcGIS, Create Web Apps. Accessed June 06, 2017. $<$ http://server.arcgis.com/en/server/latest/create-web-apps/windows/about-webgis.htm>.

-. 2017. Developers ArcGIS, Feature Layer. Accessed June 12, 2017. $<$ https://developers.arcgis.com/javascript/3/jsapi /featurelayer-amd.html $>$.

—. 2017. Developers ArcGIS, Legend Widget. Accessed June 12, 2017. $<$ https://developers.arcgis.com/javascript/ latest/api-reference/esri-widgetsLegend.html $>$. 
—. 2017. Developers ArcGIS, Map View. Accessed June 08, 2017. $<$ https://developers.arcgis.com/javascript/latest/api-reference/esri-viewsMapView.html >.

-. 2017. Developers ArcGIS, MapView, Map Image Layer. Accessed June 8, 2017. $<\mathrm{https}$ ://developers.arcgis.com/javascript/latest/api-reference/esri-layersMapImageLayer.html >.

-. 2017. Developers ArcGIS, Search Widget. Accessed June 12, 2017. $<$ https://developers.arcgis.com/javascript/latest/api-reference/esri-widgetsSearch.html>.

-. 2017. Developers ArcGIS, Web App Builder for ArcGIS (Developer Edition). Accessed June 12, 2017. <https://developers.arcgis.com/web-appbuilder/ >.

—. 2017. Dojo Toolkit, domReady, PlugIns. Accessed June 12, 2017. $<$ https://dojotoolkit.org/reference-guide/1.10/loader/amd.html >.

Hansen, Rex, and Rich Zwaap. 2015. ArcGIS Blog. 01 26. Accessed 08 16, 2017. https://blogs.esri.com/esri/arcgis/2015/01/26/version-3-3-of-the-arcgis-api-forsilverlight-and-arcgis-viewer-for-silverlight-now-available/.

Kraak, Menno-Jan. 2004. "The role of the map in a Web-GIS environment." Geographical Systems 1-11.

Law, Derek. 2013. "Understanding architecture, deployment, and workfl ows." ArcGIS for Server 1016.

Law, Derek. 2013. "Understanding architecture, deployment, and workflows." ArcGIS for Server 101 6. <http://www.esri.com/esri-news/arcuser/spring-2013/arcgisfor-server-101>.

Liu, Xuhui, Jizhong Han, Yunqin Zhong, Chengde Han, and Xubin He. 2009. "Implementing WebGIS on Hadoop: A Case Study of Improving Small File I/O Performance on HDFS." IEEE 1-2.

Lu, Han, Wang Nihong, Wan Chang, and Chi Yujia. 2010. "The Research on the WebGIS Application Based on the J2EE Framework and ArcGIS Server." 2010 International Conference on Intelligent Computation Technology and Automation 1-2.

Ndegwa, Amos. 2016. Maxcdn. 05 31. Accessed 08 20, 2017. https://www.maxcdn.com/one/visual-glossary/web-application/.

Oracle. 1999. Help Center. Accessed May 25, 2017. $<$ https://docs.oracle.com/cd/E19957-01/816-6409-10/intro.htm>. 
Paulson, Linda Dailey. 2005. "Building Rich Web Applications with Ajax." Industry Trends (IEEE Computer Society) 14-17.

Peng, Zhong Ren, and Ming Hsiang Tsou. 2003. Internet GIS: Distributed Geographic Information Services for the Internet and Wireless Network 1st Edition. San Francisco, USA: John Wiley and Sons Inc.

Rubalcava, Rene. 2015. ArcGIS Web Development. Shelter Island, NY: Manning Publications Co.

-. 2015. ArcGIS Web Development. Shelter Island, NY: Manning Publications Co.

Segue, Technologies. 2013. Segue Technologies. 05 01. Accessed 08 18, 2017. http://www.seguetech.com/client-server-side-code/.

Svensson, Björn. 2014. ArcGIS Blog. 11 25. Accessed 8 16, 2017. https://blogs.esri.com/esri/arcgis/2014/11/25/arcgis-for-flex-3-7-released/\#more44136.

w3School. n.d. w3school, <style >. Accessed July 15, 2017. $<$ https://www.w3schools.com/tags/tag_style.asp $>$.

w3schools. 1999-2017. w3schools, <link>. Accessed July 15, 2017. $<$ https://www.w3schools.com/tags/tag_link.asp $>$.

Winkelman, Roy. 2004. Florida Center for Instructional Technology. Accessed 08 18, 2017. https://fcit.usf.edu/websites/chap1/chap1.htm.

Wodehouse, Carey. 2015. Upwork. 05 05. Accessed 08 18, 2017. https://www.upwork.com/hiring/development/how-scripting-languages-work/.

Xulin , Liu, Zhao Wenfang, and Liu Guohong. 2008. "Meteorological Information Display and Query System Based on WebGIS." Applied Meterological Science. 